\title{
Quality Growth: From Process to Product Innovation along the Path of Development*
}

\author{
Esteban Jaimovich ${ }^{\dagger}$
}

February 2017

\begin{abstract}
We propose a demand-driven growth theory where process innovations and product innovations fulfil sequential roles along the growth path. Process innovations must initially set the economy on a positive growth path. However, process innovations alone cannot fuel growth forever, as their benefits display an inherent tendency to wane. Product innovations are therefore also needed for the economy to keep growing in the long run. When the economy fails to switch from a growth regime steered by process innovation to one driven by product innovation, $\mathrm{R} \& \mathrm{D}$ effort and growth will eventually come to a halt. However, when the switch to a product innovation growth regime does take place, a virtuous circle gets ignited. This happens because product innovation effort not only keeps growth alive when incentives to undertake process innovation diminish, but it also regenerates profit prospects from further process innovation effort.
\end{abstract}

Keywords: Endogeneous Growth, Process and Product Innovation, Nonhomothetic Preferences, Quality Ladders.

JEL Classifications: O30, O31, O41

${ }^{*}$ We would like to thank Valentina Corradi, Paul Levine, Vincenzo Merella, Ignacio Monzon, Manuel Oechslin and Gonzague Vannoorenberghe for comments and suggestions.

${ }^{\dagger}$ University of Surrey. Mailing address: School of Economics, Guildford, GU2 7XH, United Kingdom. Email: e.jaimovich@surrey.ac.uk 


\section{Introduction}

Process and product innovations are two key determinants behind sustained economic growth. Process innovations introduce technological improvements that allow an expansion in the quantity of goods that an economy can deliver. Product innovations foster growth instead by bringing to the market goods of higher quality than those previously available. This paper presents a demand-driven growth theory in which both types of innovations fulfil crucial roles, and where their respective roles display a specific sequential timing. Our theory shows that process innovations must precede product innovations along the path of development. Yet, while process innovations can initially set the economy on a positive growth path, they cannot sustain rising incomes perpetually. Long-lasting growth requires that the economy is also able to start generating product innovations at some point. The reason for this is that the incentives to invest in process innovations tend to wane as physical production continuously expands.

Our model features an economy with a vertically differentiated good, available in a number of (vertically ordered) quality levels. All the quality levels are produced with technologies that use labour as their sole input. Both labour productivity and the degree of vertical differentiation are endogenous to the model. Labour productivity increases as a result of process innovations. In particular, process innovations lower the costs of production (in terms of hours of labour), leading to an increase in the physical quantities that may be produced with a given amount of labour. Product innovations instead allow the introduction of better quality versions of the vertically differentiated good.

Innovations are the outcome of purposeful research and development effort. Hence, investment in process and in product innovations will be the endogenous response to the potential profit associated to each of them. The underlying force leading to their different timings along the growth path stems from our demand side. Individuals exhibit nonhomothetic preferences along the quality dimension. In particular, their willingness to pay for quality upgrading increases as their incomes rise. An implication of this is that product innovations tend to become increasingly profitable along the growth path, since product innovators can charge higher markups when they face richer consumers. However, our nonhomothetic demand structure entails also a flip side. At early stages of development, the economy must rely on process innovations as the source of income growth. This is because the low willingness to pay for quality by consumers with low incomes stifles profit opportunities for product innovators.

Our theory then shows that when incomes are still low process innovation must become the leading actor. Product innovation takes over a more prominent role instead in more mature economies. Furthermore, such transition from process to product innovation effort proves es- 
sential for sustaining growth in our model. In a context where individuals display decreasing marginal utility on physical consumption, process innovations bring about two opposing dynamic forces. On the one hand, they drive the marginal utility of consumption down. Thus, the prospects of future profits from process innovation are endogenously dampened by current process innovation efforts. On the other hand, the higher quantity of consumption allowed by process innovations is exactly what spurs profit prospects from product innovation effort. The tension between these two countervailing forces means that an economy may or may not succeed in eventually switching from a growth path steered by process innovation to one steered by product innovation. When it fails to do so, growth will eventually come to a halt due to the negative effect of decreasing marginal utility on process innovation profits.

The switch to a product innovation growth regime can in turn ignite a virtuous circle with further process innovation down the road. The incapacity of cost-cutting innovations to spur growth perpetually lies in that a continuous expansion in quantity of production must struggle against the decreasing marginal utility of (physical) consumption that it simultaneously leads to. This struggle makes it increasingly hard to keep profit prospects from process innovation high enough to sustain it forever. Product innovation relaxes this inherent tension, since higher quality goods yield greater utility per unit of physical consumption. In other words, by raising the intrinsic quality of goods offered in the economy, product innovation is able to make the decreasing marginal utility of (physical) consumption less pressing, and thereby regenerate profit prospects from further process innovation effort.

Our theory yields thus a model where long-run growth stems from a positive feedback loop between cost-cutting and quality-enhancing innovations. The endogenous growth literature has produced several models where growth results from the interplay of different types of innovation effort, such as general purpose technologies and sector-specific complementary inputs [e.g., Bresnahan and Trajtenberg (1995), Helpman and Trajtenberg (1998a, 1998b)], fundamental research/breakthroughs and secondary development [e.g., Jovanovic and Rob (1990), Aghion and Howitt (1996), Redding (2002)], invention and learning-by-doing [e.g., Young (1993), Stein (1997)]. All these models share a common trait: there exists one fundamental source of longrun growth that interacts with a transitional and bounded source of growth linked to the fundamental technology. Our model departs from the notion of fundamental and secondary sources of technical change. We look at the specific case of process and product innovations as potentially independent sources of technical change, but ultimately unable to sustain unbounded growth without one another. This, in turn, leads to a specific sequential role by each type of innovation along the growth path, which is the core message of this paper. 
The number of articles dealing separately with either process or product innovation effort in the endogenous growth literature is certainly huge. However, it is hard to find models where both are explicitly involved together in steering the economy along the growth path, while at the same time playing a distinctive role as growth engines. ${ }^{1}$ The only exception that we are aware of is Foellmi, Wuergler and Zweimüller (2014). They build a growth model where firms must choose between product innovations to introduce new luxury goods that will be consumed only by the rich, or process innovations that turn luxury goods into mass consumption goods also available to the poor. Their model depicts situations where this type of product cycle takes place as the optimal behaviour by firms, and use it to explain how some new goods first introduced during the 20th century have later on become available as mass consumption goods (e.g., automobiles, refrigerators, etc.). ${ }^{2}$ The main focus of our model is somewhat different, as it studies how the interplay between process and product innovation efforts can sustain a continuous increase in incomes in the long run, and how the preeminence of each type of innovation tends to shift along the growth path. In that sense, our model is mostly concerned with how an economy may keep growing beyond a mass consumption economy, in a context where rising incomes increasingly tilt consumer preferences towards quality expansion (and away from quantity expansion). ${ }^{3}$

\footnotetext{
${ }^{1}$ Models where growth is the result of the of new technologies that allow an increase in physical production (i.e., process innovations) can be found in: Shleifer (1986), Aghion and Howitt (1992), Jones (1995), Kortum (1997). Examples of models where growth is driven by the introduction of final goods of higher quality than before (i.e., product innovations) are: Segerstrom et al. (1990), Grossman and Helpman (1991a, 1991b), Stokey (1991), Segerstrom (1998). A third type of innovation, which is neglected by our model, is that one that leads to a horizontal expansion in the variety of goods, as in Judd (1985), Romer (1990), Grossman and Helpman (1991c, Ch. 3), Young (1993). We relegate to the concluding section a brief discussion on the possible effects of introducing variety-expanding innovations within the context of our model. Finally, there exists a small literature that incorporates vertical and horizontal innovations into growth models [e.g., Peretto and Connolly (2007), Sorger (2011), Chu, Cozzi and Galli (2012)]. These articles, however, focus on the trade-offs faced by innovators when choosing between those two types of innovations, rather than on the interplay (and transition) between them along the growth path.

${ }^{2}$ Matsuyama (2002) also studies an endogenous growth model where goods initially affordable to the rich become gradually mass consumption goods affordable to all individuals. In his model, however, technological change is not the result of purposeful R\&D effort, but it arises because of industry-specific learning-by-doing.

${ }^{3}$ Foellmi and Zweimüller (2006) also present a demand-driven endogenous growth model where individuals display non-homothetic preferences. Their model differs from ours substantially, with two key differences: i) in their model there is no quality differentiation (their nonhomotheticities are the result of hierarchical preferences with a horizontal continuum of goods); ii) their model features only cost-cutting innovations, which is combined with a setup cost that must be incurred to open new sectors/product lines.
} 
A key aspect behind our demand-driven growth model is therefore the nonhomotheticity of preferences along the quality dimension; in particular, the notion that willingness to pay for quality upgrading rises as people get richer. This is in fact a property of the preference structure that has been previously incorporated in several trade models [e.g., Flam and Helpman (1987), Murphy and Shleifer (1997), Fajgelbaum, Grossman and Helpman (2011, 2015), Jaimovich and Merella $(2012,2015)]$, and it has also been widely supported both by household-level data based on consumer surveys [e.g., Bils and Klenow (2001)] and bilateral trade flows data [e.g., Hallak (2006) and Choi et al. (2009)]. In our model, quality upgrading arises endogenously as the result of firms' effort to cater to consumers with rising incomes, a phenomenon that has also received support by a growing strand of empirical papers; e.g. Verhoogen (2008), Brambilla et al. (2012), Manova and Zhang (2012), Bas and Strauss-Kahn (2015), Flach (2016). In addition to such quality-upgrading effort in response to rising incomes, our theory also predicts a gradual shift from process innovation to product innovation along the growth path. This required growth transition echoes the current policy discussions summarised in the 'Made in China 2025' initiative, which aims to bolster quality of production in the Chinese manufacturing sector. ${ }^{4}$ Moreover, such dynamic transition seems also to be in line with the R\&D behaviour by firms in countries with different incomes, as shown below in Table 1.

Table 1 displays a series of simple correlations between the innovation intensity by type of innovation at the firm level, and the income per head of the country where the firm is located. (Some additional correlations expanding on the results in Table 1 are displayed in Appendix B.) The data on innovation intensity by type of innovation (process innovation vs. product innovation) is taken from the Eurostat Community Innovation Survey (CIS), which collects information about the innovation activity by enterprises. ${ }^{5}$ The CIS asks the surveyed firms if they have introduced innovations during the previous two years, and whether these innovations pertain to process innovation or product innovation (or both). ${ }^{6}$

\footnotetext{
${ }^{4} \mathrm{~A}$ quick summary of the main objectives of the 'Made in China 2025' initiative can be found on https://www.csis.org/analysis/made-china-2025, where explicit reference is made to the fact one of the guiding principles 'are to have manufacturing be innovation-driven, [and] emphasize quality over quantity [...]' See also the explicit reference by China's Premier Li Keqiang in http://www.china.org.cn/business/201503/30/content_35192417.htm to the fact that '[China] will redouble its efforts to upgrade from a manufacturer of quantity to one of quality'. One of the stated reasons behind the 'Made in China 2025' initiative is to be able to meet the higher demand for quality and high-end products by the growing middle-income Chinese population.

${ }^{5}$ Table 1 uses the CIS that covers the innovation activities of firms during 2004-06. This survey was conducted in the 25 EU members states (as of 2006), plus Norway, Bulgaria, Romania, Croatia and Turkey.

${ }^{6}$ The CIS specifies a process innovation as follows 'A process innovation is the implementation of a new or significantly improved production process, distribution method, or support activity for your goods or services.
} 
The first column in Table 1 regresses the share of surveyed firms in each country that have introduced either process innovations or product innovations (or both) during the surveyed period on the income per head of each country. The correlation between the two variables is positive and highly significant, suggesting that firms in richer economies tend to introduce more innovations (of any type) than those in poorer economies. More revealing of how the nature of the innovation activities undertaken by firms changes over the growth path are the results in the second and third column of Table 1. The second column considers as the dependent variable only those firms that have introduced process innovations, while the third column considers only those firms that have introduced product innovations. In both cases, we see again positive and significant correlations. However, the magnitude of the correlation between the share of firms doing product innovation and income per head is stronger than that one obtained when considering the share of firms doing process innovation. Another way to see how the relevance of the different types of innovation effort shifts along the growth path is portrayed in column four. This column uses as dependent variable the ratio of firms that introduced product innovations over those reporting the introduction of process innovations. Regressing this ratio on the income per head of the country where those firms are located we obtain again a correlation coefficient that is positive and significant. ${ }^{7}$

Taken together, the set of correlations displayed in Table 1 point out towards an interesting pattern: while $R \& D$ activities are larger in richer countries than in poorer ones, this behaviour is more pronounced for product innovations than for process innovations. In particular, the cross-country data seems to suggest that the prominence of product innovation effort relative to process innovation effort is greater in countries with higher income per capita. Our paper offers a demand-driven endogenous growth model that is able rationalise these correlations. ${ }^{8}$

[...] [It] excludes purely organisational innovations.'. As for product innovation, the CIS defines 'A product innovation is the market introduction of a new good or service or a significantly improved good or service with respect to its capabilities, such as improved software, user friendliness, components or sub-systems [...]'.

${ }^{7}$ Although there exists a small empirical literature that investigates the behaviour of firms in terms of R\&D investment, differentiating between process and product innovation [e.g., Cohen and Klepper (1996), Huergo and Jaumandreu (2004), Parisi et al. (2006), Harrison et al. (2014)], none of these papers uses data collected from a large and diverse sample of different countries. These studies either use firm-level data from one single country (like Cohen and Klepper (1996) for US, Huergo and Jaumandreu (2004) for Spain, or Parisi et al. (2006) for Italy), or from a small number of countries with similar levels of income (like Harrison et al. (2014) for France, Germany, Spain and UK). As a result, this literature is silent about correlations between income per capita and intensity of investment in process innovation relative to product innovation.

${ }^{8}$ There are certainly several other mechanisms that can lead to correlation patterns as those in Table 1. For example, they could partly be determined by supply-side factors, such as differences in the stock of human 
Table 1: Process Innovation and Product Innovation Intensity at Different Income Levels

\begin{tabular}{|c|c|c|c|c|}
\hline & \multicolumn{4}{|c|}{ Dependent Variable } \\
\hline & $\begin{array}{l}\text { ratio of firms doing process } \\
\text { and/or product innovation }\end{array}$ & $\begin{array}{r}\text { ratio of firms doing } \\
\text { process innovation } \\
\end{array}$ & $\begin{array}{r}\text { ratio of firms doing } \\
\text { product innovation } \\
\end{array}$ & $\begin{array}{l}\text { ratio of firms doing product } \\
\text { to firms doing process innov. }\end{array}$ \\
\hline GDP per head (PPP) & $\begin{array}{c}0.049 * * * \\
(0.012)\end{array}$ & $\begin{array}{l}0.020 * \\
(0.010)\end{array}$ & $\begin{array}{l}0.040 * * * \\
(0.009)\end{array}$ & $\begin{array}{c}0.074 * * * \\
(0.025)\end{array}$ \\
\hline R-squared & 0.37 & 0.12 & 0.42 & 0.24 \\
\hline Number countries & 30 & 30 & 30 & 30 \\
\hline
\end{tabular}

The rest of the paper is organised as follows. Section 2 presents the setup and main assumptions of the model. Section 3 studies a simplified framework with two quality versions and where the only source of technical change is process innovations, showing that growth is eventually bound to come to a halt. Section 4 allows also the introduction of product innovations into the two-quality-version model, and shows that product innovations may help sustaining growth for longer. Section 5 extends the model to an environment with an infinite number of quality levels, which may allow positive growth in the long run. Section 6 provides some concluding remarks. All relevant proofs are relegated to the appendices.

\section{Setup of the Model}

Life evolves in discrete time over an infinite horizon, starting in $t=1$. In each period $t$ a unit mass of individuals is spontaneously born. Individuals live for one period only. All individuals are endowed with two units of time: one unit of labour time and one unit of spare time. Labour time is supplied inelastically to firms. The unit of spare time may instead be used as leisure time or, alternatively, to undertake $\mathrm{R} \& \mathrm{D}$ effort. ${ }^{9}$

capital or financial development across economies (if either human capital or financial development were more relevant to product innovations than to process innovations). In that respect, we take the correlations in Table 1 simply as motivational evidence to our theory (and not as uniquely determined by it). Moreover, the additional regressions in Appendix B intend to provide some robustness checks to some of those possible concerns.

${ }^{9}$ The assumption that the unit of labour time is supplied inelastically is posed only in the sake of analytical simplicity, as it allows us to focus only on the trade-off between leisure and R\&D effort. Appendix C shows how our main results hold through when we extend the model to let individuals also substitute labour time for leisure. In addition, that extension also relaxes the $\{0,1\}$ discrete allocation of leisure versus effort, by allowing agents to split their time endowments between leisure and effort within a unit time interval. 
The economy's output consists of a final consumption good, which is potentially available in a discrete number of vertically ordered quality levels: $q \in Q$. We normalise the lowest value in the set $Q$ to unity. Henceforth, we will recurrently refer to the different quality levels as quality versions, and to the lowest quality level $(q=1)$ as the baseline quality.

\subsection{Technologies}

Production takes place within firms. Firms are risk neutral and are active for one period only (that is, a firm that operates in period $t$ will close down at the end of $t$ ). There is free entry to the final good sector and opening a new firm entails no setup cost.

In $t=1$ the economy inherits a technology from the pre-historic period $t=0$. The inherited technology allows transforming one unit of labour into one unit of the consumption good, but only in its baseline quality version $q=1$. All firms active in $t=1$ have free access to the technology inherited from $t=0$. In addition to this, individuals may undertake innovation effort in order to create blueprints for generating new technologies. In what follows, we explain in further detail the different set of technologies available in each period $t$ and how they originate.

\subsubsection{New and Inherited Technologies I: the effects of process innovation}

All agents born in period $t$ inherit at birth all the technological know-how that has been generated before $t$ by prior events of process innovation. We broadly refer to all the technologies that were already available before period $t$ as inherited technologies. Inherited technologies may be further improved upon through current process innovation effort. When an individual alive in $t$ exerts process innovation effort, he will create a blueprint that may lead to a new technology with higher labour productivity than that one available in $t-1$.

We assume that, in each period $t$, there is a unit mass of process innovation blueprints that may possibly be created; we denote this set of potential blueprints by $B_{t}^{p}=[0,1]$. We also assume that only one of these blueprints will turn out to be successful (ex post) in raising labour productivity; we label this successful blueprint by $s_{t}^{p}$, where $s_{t}^{p} \in B_{t}^{p}$. Neither individuals nor firms know (ex-ante) which element of $B_{t}^{p}$ will turn out to be $s_{t}^{p}$. They all know, however, that all elements in $B_{t}^{p}$ carry the same probability to become $s_{t}^{p}$, and that there is always one element that will become $s_{t}^{p}$. Both firms and individuals find out which element of $B_{t}^{p}$ turns out to be $s_{t}^{p}$ after market exchanges of blueprints take place. (We explain the within-period timing of the model in further detail in Section 2.3.)

Note that not all potential blueprints will be necessarily created in any particular period $t$. It proves then convenient to let $b_{t}^{p} \subseteq B_{t}^{p}$ denote the subset of blueprints that were actually 
created as a result of process innovation effort in $t$. A process innovation will be generated in a generic period $\tau$ if and only if $s_{\tau}^{p} \in b_{\tau}^{p}$. The number of process innovations generated before period $t$ can be written as follows:

$$
R_{t-1}=\left\{\begin{array}{ll}
\sum_{\tau=1}^{t-1} 1\left\{s_{\tau}^{p} \in b_{\tau}^{p}\right\} & \text { if } t \geq 2 \\
0 & \text { if } t=1
\end{array},\right.
$$

where $1\left\{s_{\tau}^{p} \in b_{\tau}^{p}\right\}$ represents an index function that is equal to 1 when $s_{\tau}^{p} \in b_{\tau}^{p}$, and 0 otherwise.

We can now describe formally the set of technologies available to firms active in period $t$ resulting from process innovation effort.

Assumption 1 Consider some generic period $t \geq 1$. The technological options resulting from process innovation effort that are available to firms active in period $t$ are the following ones:

(i) Inherited technology: If a firm active in $t$ does not purchase any process innovation blueprints, the firm will be able to produce

$$
1+\sigma R_{t-1}
$$

units of the baseline quality, $q=1$, with each unit of labour it hires, where $\sigma>0$ and $R_{t-1}$ is given by (1).

(ii) New technologies: If a firm active in $t$ purchases a bundle of process innovation blueprints, and the bundle contains $s_{t}^{p}$, the firm will be able to produce

$$
1+\sigma R_{t-1}+\sigma
$$

units of the baseline quality, $q=1$, with each unit of labour it hires.

The first part of Assumption 1 stipulates that the effects of process innovation on labour productivity accumulate over time, and are (freely) transferred to the next generations as inherited technologies. The second part describes the effects of current process innovation: successful blueprints boost labour productivity by $\sigma>0$ units relative to the inherited technology. ${ }^{10}$

\subsubsection{New and Inherited Technologies II: the effects of product innovation}

The economy may also have available improved technologies that originate from product innovation effort. Product innovation effort leaves labour productivity unchanged, but it allows the production of higher quality versions of the consumption good.

\footnotetext{
${ }^{10}$ Since $R_{0}=0$, Assumption 1 implicitly states that in $t=1$ the inherited technology is the pre-historic technology, allowing firms to produce one unit of $q=1$ with each unit of labour hired.
} 
Analogously as done for process innovations, we now assume that in each period $t$ there is a unit mass of product innovation blueprints that may possibly be created, and denote this set by $B_{t}^{q}=[0,1]$. Only one of these blueprints, denoted by $s_{t}^{q} \in B_{t}^{q}$, will be successful (ex post) in generating quality upgrading. No one knows ex-ante which element will turn out to be $s_{t}^{q}$, but everyone knows that there is always one $s_{t}^{q}$ and that all elements of $B_{t}^{q}$ are equally likely to become $s_{t}^{q}$. Again, both firms and individuals find out $s_{t}^{q}$ after market exchanges of (product innovation) blueprints take place.

Assumption 2 below summarises the quality upgrading effect of product innovation effort. It also states the (physical) productivity of labour at the different levels of quality in which the final good is available. To do this, we label by $q_{t}$ the highest quality version that is available at the end of period $t$. It proves convenient again to specifically label the subset of blueprints that were actually created as a result of product innovation effort in $t$, which we do by $b_{t}^{q} \subseteq B_{t}^{p}$.

Assumption 2 Consider some generic period $t \geq 1$. The technological options resulting from product innovation effort that are available to firms active in period $t$ are the following ones:

(i) Inherited technology: If a firm active in $t$ does not purchase any new blueprints, the firm will be able to produce

$$
\frac{1+\sigma R_{t-1}}{q_{t-1}}
$$

units of the consumption good in the quality level $q_{t-1}$, where

$$
q_{t-1}=\left\{\begin{array}{ll}
1+\rho \sum_{\tau=1}^{t-1} 1\left\{s_{\tau}^{q} \in b_{\tau}^{q}\right\} & \text { if } t \geq 2 \\
1 & \text { if } t=1
\end{array},\right.
$$

with $\rho>0$.

(ii) New technologies: If a firm active in $t$ purchases a bundle of product innovation blueprints, and the bundle contains $s_{t}^{q}$, the firm will be able to produce

$$
\frac{1+\sigma R_{t-1}}{q_{t}}
$$

units of the consumption good in the quality level $q_{t}$, where $q_{t}=q_{t-1}+\rho$.

Assumption 2 describes how a successful product innovation blueprint in $t, s_{t}^{q}$, allows the production of a version of the good whose quality level is $\rho>0$ units higher than the one that was available at the end of $t-1$ (namely, $\left.q_{t}=q_{t-1}+\rho\right)$. It also states how past product innovations alter future production possibilities: the quality version $q_{t}$ will also be readily available from $t+1$ onwards as an inherited technology, without the need of any further product innovation effort. 
Two additional remarks are worth stressing here. Firstly, Assumption 1 and 2 taken together imply that past process innovations generate productivity improvements that are not qualityspecific. More precisely, the numerators in (2) and (3) entail that improvements in labour productivity owing to prior process innovations apply identically to all the existing quality versions of the consumption good. ${ }^{11}$ Secondly, the denominators in (2) and (3) entail that the unit labour requirements are greater for higher quality versions of the consumption good than for lower quality ones.

\subsection{Preferences}

The utility function of an individual alive in period $t$ is given by:

$$
U_{t}=\ln \left[\sum_{q \in Q_{t}} \max \left\{q x(q),[q x(q)]^{q}\right\}\right]+\eta(1-\varepsilon) .
$$

In (4), $x(q)$ denotes the quantity of the quality version $q \in Q_{t}$ consumed by the individual, and $Q_{t} \subseteq Q$ is the subset of quality versions available in period $t .{ }^{12}$ Next, $\varepsilon$ is an index function that takes the value of 1 if the individual decided to undertake $R \& D$ effort (either in the form of process or product innovation) and 0 if he instead chose to use his time endowment as leisure, with $\eta>0$ being the utility of leisure.

Two important mathematical properties of (4) are worth mentioning now. Firstly, since the lowest value of the set $Q_{t}$ is $q=1$, the term $\sum_{q \in Q_{t}} \max \left\{q x(q),[q x(q)]^{q}\right\}$ turns out to be a sum of convex functions in $x(q)$. As a consequence of this, in the optimum, individuals will select a corner solution for their consumption plan; that is, a solution characterised by $x(q)>0$ for some $q \in Q_{t}$ and zero for all other quality versions of the good. Secondly, the expression $\max \left\{q x(q),[q x(q)]^{q}\right\}$ in (4) means that higher quality versions magnify the level of utility that an individual obtains from a given physical amount of the consumption good. ${ }^{13}$ Moreover, this

\footnotetext{
${ }^{11}$ While the assumption that prior process innovations apply identically to all quality versions of the good may seem extreme, all our main results would still hold when process innovations spillovers applied only partially to higher-quality versions of the good, similarly to Jovanovic and Nyarko (1996) or Redding (2002). Essentially, what our model needs is that the positive income effects resulting from (past) process innovations do not totally vanish when introducing a product innovation.

${ }^{12}$ Naturally, before any product innovation takes place, $Q_{t}=\{1\}$; that is, the only element of $Q_{t}$ is $q=1$.

${ }^{13}$ The expression $\max \left\{q x(q),[q x(q)]^{q}\right\}$ in (4) ensures that the quality dimension $q$ is always a desirable feature to consumers. As it will become apparent in the next sections, given the assumptions of our model, in equilibrium it will always be the case that $q x(q) \leq[q x(q)]^{q}$ will hold for all individuals. All the following results in our model will thus be based on the part of (4) that exhibits the exponential functional form $[q x(q)]^{q}$. $(\mathrm{A}$ formal proof of this fact is provided in Appendix E.)
} 
magnifying effect becomes stronger the larger the value of physical consumption $x(q)$. This is a crucial feature of our model, as it will lead to a non-homothetic behaviour in the demand for quality. In particular, the exponential effect of $q$ on physical consumption $x(q)$ leads to demand functions where the willingness to pay for higher quality versions of the final good is increasing in the level of spending of the consumer. ${ }^{14}$

\subsection{Timing of Events}

In each period $t$, actions take place with the following within-period timing:

1. Agents are born and inherit all the technologies that were available at the end of $t-1$.

2. Each individual $i$ decides whether to use his spare time endowment $\left(\varepsilon_{i}\right)$ as leisure or innovation effort. In case of the latter, they must also choose between process or product innovation effort. When choosing process innovation effort (resp. product innovation effort), they must also select which specific blueprint to create from the set $B_{t}^{p}$ (resp. from the set $\left.B_{t}^{q}\right)$.

3. Individuals sell their innovation blueprints to firms.

4. Nature reveals the identities of the successful blueprints: $s_{t}^{p} \in B_{t}^{p}$ and $s_{t}^{q} \in B_{t}^{q}$.

5. Individuals sell their labour endowments to firms. Production and consumption take place.

\section{Endogenous Growth via Process Innovation}

In this section, we study the dynamic behaviour of the economy under the assumption that only process innovation is feasible. Doing this allows a cleaner description of the conditions under which process innovation arises in equilibrium, and how it endogenously generates its own tendency to eventually stop. In addition, for most part of the paper, we further simplify the analysis by considering an environment where there exist only two potential quality versions of

\footnotetext{
${ }^{14}$ In growth models with homothetic preferences, the distinction between reductions in costs per physical unit of production (i.e., process innovation) and increases in quality per physical unit (i.e., product innovation) may usually be unclear, since those sources of technical change can often be re-labeled to become isomorphic. Our nonhomothetic preference structure in (4) actually turns the distinction between quality improvements and physical productivity improvements economically meaningful, as the income-dependent willingness to pay for quality upgrading implies that those sources of growth cannot be taken simply as isomorphic to one another.
} 
the consumption good; that is, $Q=\{1,1+\rho\}$. Nevertheless, in Section 5 we show how the model easily extends to a more general environment with an infinite number of quality versions, and the dynamic implications of this. Finally, we restrict all our analysis to symmetric equilibria under pure strategies. ${ }^{15}$

\subsection{Process Innovation Effort in $t=1$}

Consider a generic individual born in $t=1$. This agent may use his spare time endowment as process innovation effort or, else, simply enjoy it as leisure. If the individual chooses the former, he must also select the specific process innovation blueprint to create from among $B_{1}^{p}$. Since there is a unit mass of individuals and the set $B_{1}^{p}$ has also unit mass, in equilibrium, no individual will choose to create a blueprint that is also being created by another individual (in other words, there will be no duplication of blueprints in equilibrium). ${ }^{16}$

We take the baseline quality version of the consumption good as the numeraire. Recall from Assumption 1 that in $t=1$ any firm can produce one unit of the baseline quality simply by using the inherited technology. Given free entry, this implies that in equilibrium each individual will receive a wage equal to one during $t=1$. We label this wage by $w_{1}=1$.

Individuals may also receive earnings from selling the blueprints they created via process innovation effort to firms. Free entry and firm competition imply that the equilibrium price of a blueprint must equal the expected return it generates. Consider thus a hypothetical firm that purchased the blueprint that (ex post) turned out to be $s_{1}^{p}$. This firm will be able to produce $1+\sigma$ units of the baseline quality version of the final good by hiring all the available labour supply (which has unit mass). Since each unit of labour $\operatorname{costs} w_{1}=1$, the blueprint $s_{1}^{p}$ will thus yield a profit equal to $\sigma$. Recall now that firms do not know (ex ante) which blueprint will turn out to be $s_{1}^{p}$, and all blueprints in $B_{1}^{p}$ carry the same probability to become $s_{1}^{p}$. As a result, an individual alive in $t=1$ will be able to sell a process innovation blueprint to a firm for a price equal to $\sigma$ (which is the expected return it will generate). ${ }^{17}$

\footnotetext{
${ }^{15}$ There exist some parametric configurations of the model under which mixed-strategy equilibria would arise alongside symmetric pure-strategy equilibria. However, ruling out those cases does not seem to a major source of concern to our results, as when mixed-strategy equilibria do exist, they turn out to be locally unstable (see footnote 24 in Section 4.2 for some further discussion on this issue).

${ }^{16}$ The same non-duplication result will hold in every period $t$, given that the mass of agents is equal to one for all generations and all the sets $B_{t}^{p}$ have unit mass as well.

${ }^{17}$ Rigorously speaking, since we have a continuum of individuals $i$ such that $\int_{0}^{1} d i=1$, each blueprint carries a probability $d i$ to become the successful blueprint, generating an expected return $\left[\int_{0}^{1}(1+\sigma) d j-\int_{0}^{1} 1 d j\right] d i=\sigma d i$ when the firm that purchased it hires also the entire available labour supply. From now on, to keep a lighter
} 
Let $Y_{i, 1}$ denote the lifetime earnings of a generic individual $i$ at the end of $t=1$. There are, in principle, two components in $Y_{i, 1}$. The first is the earnings received as a wage, $w_{1}=1$. The second, in case individual $i$ decided to exert process innovation effort, is the payment received for selling the resulting blueprint to some firm (which is equal to $\sigma$ ). Thus, when individual $i$ invests his spare time endowment in process innovation,

$$
Y_{i, 1}\left(\varepsilon_{i, 1}=1\right)=1+\sigma
$$

Instead, if $i$ chooses to consume his spare time endowment as leisure,

$$
Y_{i, 1}\left(\varepsilon_{i, 1}=0\right)=1 \text {. }
$$

The optimal decision for $i$ will naturally depend on which of the two actions (i.e., $\varepsilon_{i, 1}=1$ or $\varepsilon_{i, 1}=0$ ) leads to a higher utility level. Using (4), it follows that a generic individual $i$ alive in $t=1$ will set $\varepsilon_{i, 1}=1$ if and only if: $\ln \left(Y_{i, 1}\left(\varepsilon_{i, 1}=1\right)\right)>\ln \left(Y_{i, 1}\left(\varepsilon_{i, 1}=0\right)\right)+\eta$. (For the rest of the paper we will assume that in case of indifference the agent chooses $\varepsilon_{i}=0$.) Hence, using (5) and (6), and noting that $Y_{i, 1}$ depends only on the action by individual $i$ (i.e., $\varepsilon_{i, 1}$ ), we can finally obtain the condition that ensures that, in equilibrium, individuals alive in $t=1$ will exert process innovation effort. Namely:

$$
\ln (1+\sigma)>\eta
$$

Otherwise, they will all set $\varepsilon_{1}=0$.

Condition (7) shows (quite intuitively) that a larger value of $\sigma$ is instrumental to sustaining an equilibrium with positive process innovation effort. An equilibrium where $\varepsilon_{1}=1$ requires that the additional utility obtained from $Y_{i, 1}\left(\varepsilon_{i, 1}=1\right)$, relative to that obtained from $Y_{i, 1}\left(\varepsilon_{i, 1}=\right.$ $0)$, more than compensates the disutility of effort incurred when $\varepsilon_{i, 1}=1$, which leads $(7)$.

\subsection{Process Innovation Effort in a Generic $t$}

Assumption 1 states that any firm active in period $t$ can freely use the inherited technology from $t-1$. Hence, without needing to buy any new blueprints, any firm active in $t$ will be able to produce $1+\sigma R_{t-1}$ units of baseline quality with each unit of labour it hires. Competition among firms for workers will thus lead to an equilibrium wage:

$$
w_{t}=1+\sigma R_{t-1} .
$$

notation, we disregard this measure issue and simply write $\sigma$ as the expected return of any process innovation blueprint. Such abuse of notation, in turn, entails that we think of the utility of leisure as having a comparable measure to individual income (in other words, we take the utility of leisure of $i$ as being equal to $\eta d i$ ). 
Any new process innovation blueprint created in period $t$ will boost labour productivity, in expectation, by $\sigma$ units. Therefore, in any period $t$, the price at which individuals will be able to sell their newly created blueprints will be equal to $\sigma$.

Using this result, together with (8), we can now generalise (5) and (6) for a generic economy whose inherited technology embodies $R_{t-1}$ past process innovations. In this case, the lifetime earnings of an individual alive in $t$ as a function of $\varepsilon_{t}$ will be given by:

$$
\begin{aligned}
& Y_{t}\left(\varepsilon_{t}=1\right)=1+\sigma R_{t-1}+\sigma \\
& Y_{t}\left(\varepsilon_{t}=0\right)=1+\sigma R_{t-1}
\end{aligned}
$$

From (9) and (10), it follows that a necessary and sufficient condition for an equilibrium with $\varepsilon_{t}^{*}=1$ to hold, is that $\ln \left(1+\sigma R_{t-1}+\sigma\right)>\ln \left(1+\sigma R_{t-1}\right)+\eta$. This condition leads to the following result.

Lemma 1 Consider an economy in period $t$ which up until $t-1$ has gone through $R_{t-1}$ periods where, in equilibrium, individuals used their spare time endowment as process innovation effort. Then, the equilibrium in period $t$ will feature $\varepsilon_{t}^{*}=1$ if and only if:

$$
\ln \left(1+\frac{\sigma}{1+\sigma R_{t-1}}\right)>\eta .
$$

The result in Lemma 1 generalises condition (7) to any period $t .{ }^{18}$ This simple generalisation yields also some additional insights. First, notice that $\sigma /\left(1+\sigma R_{t-1}\right)$ is strictly decreasing in $R_{t-1}$, and it converges to zero when $R_{t-1} \rightarrow \infty$. Hence, there will always be a value of $R_{t-1}$ that is large enough such that (11) will fail to hold, and period $t$ will thus feature an equilibrium with $\varepsilon_{t}^{*}=0$ (that is, where individuals in $t$ do not exert process innovation effort). Moreover, the ratio $\sigma /\left(1+\sigma R_{t-1}\right)$ is strictly increasing in $\sigma$. As a result, the threshold value of $R_{t-1}$ beyond which process innovation will necessarily stop tends to be greater for economies with a larger $\sigma$. The exact value of this threshold is pinned down by the level of $R_{t-1}$ that makes left-hand side of (11) equal to $\eta$, namely:

$$
\bar{R}(\sigma) \equiv \frac{1+\sigma-e^{\eta}}{\sigma\left(e^{\eta}-1\right)}
$$

Using (12), we can now observe that Lemma 1 implies that there is a maximum number of (subsequent) periods such that the economy will be able to exhibit an equilibrium with positive

\footnotetext{
${ }^{18}$ It is straightforward to observe that conditions (7) and (11) coincide when $R_{t-1}=0$.
} 
process innovation effort. Furthermore, the fact that $\bar{R}^{\prime}(\sigma)>0$ also means that economies with a larger $\sigma$ are able to sustain an equilibrium with positive process innovation effort for longer. ${ }^{19}$

To conclude this section, we can finally describe the full dynamic behaviour of $R_{t}$ in this version of the model where only process innovation effort is allowed. In order to deal with integer issues, we introduce one additional threshold:

Definition 1 Let $\bar{t}(\sigma) \equiv \operatorname{integer}\{\bar{R}(\sigma)+1\}$, where $\bar{R}(\sigma)$ is defined by (12).

Proposition 1 When condition (7) holds, implying that $\bar{R}(\sigma)>0$, the economy will experience an equilibrium with positive process innovation effort in all periods from $t=1$ until $t=\bar{t}(\sigma) \geq 1$. In any period $t>\bar{t}(\sigma)$, the economy will experience an equilibrium without process innovation effort. This, in turn, implies that $R_{t}=t$ whenever $t \leq \bar{t}(\sigma)$, while $R_{t}=\bar{t}(\sigma)$ for all $t>\bar{t}(\sigma)$.

Proposition 1 shows that, when condition (7) holds, the economy will keep investing in process innovation in each period $t \geq 1$ until reaching $t=\bar{t}$ (notice, however, that it may well be the case that $\bar{t}=1) \cdot{ }^{20}$ While this happens productivity will accordingly grow, which is reflected in the fact that $R_{t}=t$ whenever $t \leq \bar{t}$. Once the economy goes past period $\bar{t}$, process innovation effort stops forever, and $R_{t}$ remains thereafter constant and equal to $\bar{t}$.

The intuition behind the fact that process innovation eventually comes to halt hinges on the decreasing marginal utility of consumption. When an individual is contemplating whether or not to use his time endowment for process innovation, he faces a trade-off between higher consumption versus higher leisure. Setting $\varepsilon_{t}=1$ allows a level of consumption equal to $Y_{t}\left(\varepsilon_{t}=1\right)=1+\sigma R_{t-1}+\sigma$. On the other hand, $\varepsilon_{t}=0$ leads a lower level of consumption, $Y_{t}\left(\varepsilon_{t}=0\right)=1+\sigma R_{t-1}$, but it yields an additional non-pecuniary benefit, $\eta$. The difference between $Y_{t}\left(\varepsilon_{t}=1\right)$ and $Y_{t}\left(\varepsilon_{t}=0\right)$ is always equal to $\sigma$. However, as the economy goes through subsequent rounds of process innovation and $R_{t-1}$ accordingly rises, both $Y_{t}\left(\varepsilon_{t}=1\right)$ and $Y_{t}\left(\varepsilon_{t}=0\right)$ will increase. In a context with decreasing marginal utility of consumption, higher values of $Y_{t}\left(\varepsilon_{t}=1\right)$ and $Y_{t}\left(\varepsilon_{t}=0\right)$ in turn imply that the consumption gap between them tends to become less and less appealing relative to the required leisure sacrifice $\eta$.

\footnotetext{
${ }^{19}$ Notice also that when $1+\sigma \leq e^{\eta}$, we have that $\bar{R}(\sigma) \leq 0$, and no process innovation will ever take place. In fact, $1+\sigma>e^{\eta}$ is just the same condition as (7) for $t=1$.

${ }^{20}$ From now on, to lighten up notation, we will often write down the period-threshold function $\bar{t}(\sigma)$ simply as $\bar{t}$, and avoiding thus making its dependence on $\sigma$ explicit when this creates no confusion.
} 


\section{Introducing Product Innovation}

We proceed now to introduce product innovation effort into the model. We will consider that the only quality version that was available at the end of period $t-1$ was the baseline quality; namely, $q_{t-1}=1$. In this circumstance, when an individual alive in $t$ exerts product innovation effort, he will design a blueprint from the set $B_{t}^{q}$ which may eventually allow the production of the quality version $q_{t}=1+\rho$.

Before moving on to the full equilibrium analysis of the model, it proves convenient to first address the following two questions: $i$ ) how much must a firm pay to an individual for a product innovation blueprint?; $i i)$ what is the price that a firm producing the quality version $q_{t}=1+\rho$ will charge for this commodity?

Lemma 2 Consider a generic individual $i$ alive in period t who uses his spare time endowment as product innovation effort. If a firm wishes to purchase the product innovation blueprint designed by $i$, it will have to pay him:

$$
\pi_{i, t}^{q}=P_{t} \frac{1+\sigma R_{t-1}}{1+\rho}-\left(1+\sigma R_{t-1}\right),
$$

where $P_{t}$ in (13) denotes the price the firm will charge for each unit of the quality version $q=1+\rho$, should the acquired blueprint turn out to be the successful one (i.e., $\left.s_{t}^{q}\right)$, and which in equilibrium will be given by:

$$
P_{t}=(1+\rho) Y_{t}^{\rho /(1+\rho)}
$$

The first result in Lemma 2 stipulates the amount to be paid to a product innovator in $t$ $\left(\pi_{i, t}^{q}\right)$. This equals the (expected) earnings derived from selling the higher-quality version of the good, after paying the (equilibrium) wage $w_{t}=1+\sigma R_{t-1}$ for each unit of labour hired. Next, Lemma 2 shows in (14) that the price charged for the version of the good of quality $1+\rho$ rises with the lifetime earnings of the cohort alive in $t$. The responsiveness of $P_{t}$ to $Y_{t}$ is a direct implication of our preference structure in (4), where the quality index $q$ magnifies the utility derived from the physical quantity of consumption, $x(q)$. Such preference structure leads to a nonhomothetic behaviour where the willingness to pay for the higher-quality version (i.e., $q=1+\rho)$ rises with $Y_{t} \cdot{ }^{21}$

The equilibrium value of $P_{t}$ thus depends on the level of $Y_{t}$, which is itself also an equilibrium object. In particular, since $Y_{i, t}=w_{t}+\pi_{i, t}$, the level of $Y_{t}$ will be ultimately a function of the

\footnotetext{
${ }^{21}$ The equilibrium value of $P_{t}$ in (14) is that one that leaves consumers indifferent between buying the higherquality version at the price $P_{t}$ and buying the baseline quality version (which being the numeraire carries a price equal to one). Given our nonhomothetic structure, this indifference price rises with the level of income $Y_{t}$.
} 
innovation effort decisions by all individuals alive in period $t$. Equation (9) stated how $Y_{t}$ rises with subsequent rounds of process innovation effort. The following lemma complements those results when we allow for product innovation as well.

Lemma 3 Consider an economy in a generic period $t$. Suppose that up until period $t-1$ there were $R_{t-1}$ periods in which individuals used their spare time endowment as process innovation effort. In addition, suppose that $q_{t-1}=1$ (i.e., by the end of period $t-1$ only the baseline quality was available). Then, if the cohort alive in period $t$ use their spare time endowment to undertake product innovation effort, the level of $Y_{t}$ will be given by:

$$
Y_{t}=\left(1+\sigma R_{t-1}\right)^{1+\rho}
$$

Lemma 3 shows that the larger the value of $R_{t-1}$ the greater $Y_{t}$ will be. This is due to the fact that productivity improvements resulting from prior process innovations are cumulative across the different versions of the consumption good. Furthermore, it is interesting to notice that when $R_{t-1}=0$, the expression (15) yields $Y_{t}=1$. In other words, in the absence of any previous rounds of process innovations, product innovation effort cannot induce by itself a rise in incomes. Therefore, some initial rounds of process innovation effort are required in order to ignite income growth. In turn, as consumers' incomes grow owing to productivity improvements stemming from process innovation, this may endogenously generate sufficient profit incentives to start investing in product innovation at some point along the growth path. We next study how this particular growth sequence may arise as an equilibrium outcome of the model.

Before moving on to the next section, we need to add some additional notation to distinguish the type of innovation effort that individuals choose to do. We use henceforth $\varepsilon_{t, p}=1$ for process innovation effort, and $\varepsilon_{t, q}=1$ for product innovation effort in $t$. For simplicity, we continue to denote by $\varepsilon_{t}=0$ the choice of using the spare time endowment as leisure in $t$ (that is, exerting neither process nor product innovation effort).

\section{1 (Absence of) Product Innovation Effort in $t=1$}

We show first that an equilibrium where the individuals invest their spare time endowment in product innovation cannot possibly arise in $t=1$. Such an equilibrium would require that, for any generic individual $i$, the action $\varepsilon_{i, 1, q}=1$ is a best response to $\varepsilon_{1, q}^{*}=1$.

In an equilibrium where $\varepsilon_{1, q}^{*}=1$ the lifetime earnings of the cohort alive in $t=1$ would follow from (15) with $R_{t-1}=0$. This yields $Y_{1}=1$, which using Lemma 2, implies that firms would not be willing to pay anything for a product innovation blueprint. In turn, since investing 
in product innovation entails giving up the utility of leisure $\eta$, no individual would thus find it optimal to do so in this case.

The above result shows that an equilibrium where $\varepsilon_{1, q}^{*}=1$ cannot exist. Once we allow for product innovation effort, pinning down the type of equilibrium that arises in $t=1$ requires also analysing possible individual deviations to $\varepsilon_{i, 1, q}=1$ from situations where either $\varepsilon_{1, p}^{*}=1$ or $\varepsilon_{1}^{*}=0$. Consider, firstly, the case in which the cohort alive in $t=1$ exert process innovation effort in equilibrium (i.e., $\varepsilon_{1, p}^{*}=1$ ). If some generic individual $i$ decided to deviate to $\varepsilon_{i, 1, q}=1$, then he would generate a product innovation blueprint and sell it to a firm for a payment $\pi_{i, 1, q}=(1+\sigma)^{\rho /(1+\rho)}-1 .^{22}$ Given that when $i$ sets $\varepsilon_{i, 1, p}=1$ he is offered $\pi_{i, 1, p}=\sigma$, the deviation to $\varepsilon_{i, 1, q}=1$ is actually not profitable for him. ${ }^{23}$ Next, we can also observe that a deviation to $\varepsilon_{i, 1, q}=1$ from $\varepsilon_{1}^{*}=0$ cannot be optimal for a generic individual $i$ in $t=1$ either. This result follows from a similar reasoning as the one precluding the existence of an equilibrium with $\varepsilon_{1, q}^{*}=1$ : when the individuals set $\varepsilon_{1}^{*}=0, Y_{1}=1$ and product innovation blueprints would thus command a price equal $\pi_{i, 1, q}=0$, which cannot lead to a profitable deviation from $\varepsilon_{1}^{*}=0$.

In sum, this subsection shows that an equilibrium with positive product innovation effort will never arise in $t=1$. Moreover, it also shows that condition (7) in Section 3 remains still valid when the model incorporates product innovation effort as well. The next section proceeds to study whether an equilibrium with positive product innovation effort may eventually arise at some point along the growth path of the economy.

\subsection{Product Innovation Effort in a Generic $t$}

For an equilibrium with product innovation effort to arise two non-deviation conditions must be satisfied when the entire cohort of individuals alive in $t$ set $\varepsilon_{t, q}^{*}=1$. The first is that none of them must prefer to deviate to consuming their spare time endowment as leisure. The second is that none of them must prefer to deviate to exerting process innovation effort.

The previous subsection shows that the first condition above fails to be satisfied during $t=1$. The reason for this is that, in the absence of any previous process innovation effort (that is, when $R_{t-1}=0$ ), equation (15) yields $Y_{t}=1$, which (given our nonhomothetic preference structure) turns out to be too small to make product innovation effort worthwhile. Notice, however, that according to (15) the level of $Y_{t}$ when individuals in $t$ undertake product innovation is

\footnotetext{
${ }^{22}$ To obtain this using the expression in (13), note that the price that firms would be able to charge for the higher-quality version when $\varepsilon_{1, p}^{*}=1$ is $P_{1}=(1+\rho)(1+\sigma)^{\rho /(1+\rho)}$, since in this case we have that $Y_{1}=1+\sigma$.

${ }^{23}$ Notice that this result entails that, when condition (7) holds, our model (with both process and product innovation effort) will then still deliver an equilibrium with positive process innovation effort in $t=1$.
} 
increasing in $R_{t-1}$. This suggests that there may exist a value of $R_{t-1}$ large enough to support an equilibrium with product innovation effort. The next lemma lays out this result formally.

Lemma 4 Consider an economy in period t that has previously undergone $R_{t-1}$ periods in which former cohorts used their spare time endowments as process innovation effort. Suppose the entire cohort of individuals alive in $t$ set $\varepsilon_{t, q}=1$.

i) If

$$
\rho \ln \left(1+\sigma R_{t-1}\right)>\eta
$$

no single individual in t will prefer to deviate to consuming his spare time endowment as leisure.

ii) If

$$
\left(1+\sigma R_{t-1}\right)^{1+\rho}>1+\sigma R_{t-1}+\sigma
$$

no single individual in $t$ will prefer to deviate to exerting process innovation effort.

Lemma 4 presents the two non-deviation conditions that an equilibrium with product innovation must satisfy in period $t$. These conditions will only hold when $R_{t-1}$ is sufficiently large. In other words, unless the economy has previously undergone a sufficiently large number of rounds of process innovation, it will not be able to sustain an equilibrium with product innovation effort in $t$. While conditions (16) and (17) ensure the existence of an equilibrium with product innovation in $t$, they do not rule out the possibility that other types of symmetric equilibria in pure strategies may exist as well. The next proposition provides a more general description of the equilibrium that arises in a generic period $t$.

Proposition 2 Consider an economy in period t that has previously undergone $R_{t-1}$ periods in which former cohorts exerted process innovation effort, and for which both (16) and (17) hold true. Then:

i) There exists an equilibrium in period $t$ in which all individuals in $t$ exert product innovation effort (i.e., $\varepsilon_{t, q}^{*}=1$ ).

ii) The equilibrium with $\varepsilon_{t, q}^{*}=1$ is the unique pure-strategy symmetric equilibrium in period $t$, unless the following two conditions are also verified:

$$
\begin{aligned}
\ln \left(1+\frac{\sigma}{1+\sigma R_{t-1}}\right) & \leq \eta \\
\frac{\rho}{1+\rho} \ln \left(1+\sigma R_{t-1}\right) & \leq \eta .
\end{aligned}
$$

In particular, when (18) and (19) hold true, alongside with $\varepsilon_{t, q}^{*}=1$, there also exists an equilibrium where all individuals in $t$ use their spare time endowment as leisure (i.e., $\left.\varepsilon_{t}^{*}=0\right)$. 
Proposition 2 shows that when the two non-deviation conditions stipulated in Lemma 4 are satisfied, the economy will exhibit an equilibrium in period $t$ where individuals undertake product innovation effort. In addition, this equilibrium is also unique (within the class of purestrategy symmetric equilibria), unless the parametric configuration of the model is such that both (18) and (19) hold (together with the conditions in Lemma 4).

The multiple equilibria case described in Proposition 2 arises because of the possibility of coordination failures under some parametric configurations. In those cases, when the individuals alive in period $t$ expect $\varepsilon_{t}^{*}=0$ to hold, their best response to it turns out to be using their spare time endowment as leisure. Conversely, when they all expect $\varepsilon_{t, q}^{*}=1$, their best response to it is to exert product innovation effort as well.

In this paper, we are mostly interested in studying under which conditions will economies be able to support long-run growth, rather than in the possibility of coordination failures preventing (potential) growth from materialising. For this reason, in the next subsection we will disregard the equilibrium with $\varepsilon_{t}^{*}=0$, when it arises as a coordination failure in a context of multiple equilibria. Nevertheless, in Section 4.5 we will return to the issue of multiple equilibria, and provide an intuition for the mechanism leading to coordination failures. ${ }^{24}$

\subsection{From Process Innovation to Product Innovation}

Although Proposition 2 specifies the conditions that would lead to an equilibrium with product innovation effort, it still leaves one crucial question pending: whether or not an economy will actually be able to (endogenously) generate a level of $R_{t-1}$ large enough to make (16) and (17) hold simultaneously. In fact, if an economy fails to do so (because the incentives to keep undertaking further process innovation wane too quickly), an equilibrium with product innovation effort will never materialise. We proceed to study now the conditions required for a successful transition from a equilibrium with process innovation to one with product innovation.

Some additional notation will prove useful for future reference. Firstly, we will denote by $\underline{R}_{1}$ the value of $R_{t-1}$ that makes the LHS of (16) be equal to $\eta$. Namely:

$$
\underline{R}_{1} \equiv \frac{e^{\eta / \rho}-1}{\sigma}
$$

Secondly, we will denote by $\underline{R}_{2}$ the value of $R_{t-1}$ that equals the LHS of (17) to its RHS. In

\footnotetext{
${ }^{24}$ When the model yields both $\varepsilon_{t, q}^{*}=1$ and $\varepsilon_{t}^{*}=0$ as Nash equilibria, a third type of equilibrium would also arise involving mixed-strategies among product innovation effort and leisure. This mixed-strategy equilibrium is, however, locally unstable.
} 
this case, there is no general explicit solution for $\underline{R}_{2}$, which is thus defined implicitly by:

$$
\frac{\left(1+\sigma \underline{R}_{2}\right)^{1+\rho}}{1+\sigma \underline{R}_{2}+\sigma} \equiv 1 .
$$

Both $\underline{R}_{1}$ and $\underline{R}_{2}$ are strictly decreasing in $\sigma .^{25}$ When $R_{t-1}>\underline{R}_{1}$ and $R_{t-1}>\underline{R}_{2}$, there is an equilibrium in which individuals alive in $t$ will exert product innovation effort. Since both conditions must hold for this, we can simply combine $\underline{R}_{1}$ and $\underline{R}_{2}$ together by defining their envelope:

$$
\underline{R}(\sigma) \equiv \max \left\{\underline{R}_{1}, \underline{R}_{2}\right\},
$$

where in (22) we make it explicit the dependence of $\underline{R}$ on $\sigma$. The threshold $\underline{R}(\sigma)$ essentially pins down the minimum value that $R_{t-1}$ must reach for the economy to be able to switch to an equilibrium with product innovation effort in period $t$.

Since the model takes place in discrete time, in order to deal with integer issues, we must also introduce a period threshold.

Definition 2 Let $\underline{t}(\sigma) \equiv$ integer $\{\underline{R}(\sigma)+1\}$, where $\underline{R}(\sigma)$ is defined by $(22)$.

The value of $\underline{t}(\sigma)$ pins down the minimum number of periods that the economy must sustain an equilibrium with process innovation effort before it can switch to an equilibrium with product innovation effort.

Proposition 3 Consider an economy that satisfies condition (7). Depending on the specific values taken by $\bar{t}(\sigma)$ and $\underline{t}(\sigma)$, this economy may or may never be able to switch at some point to an equilibrium with product innovation effort. In particular:

i) If $\bar{t}(\sigma)<\underline{t}(\sigma)$, the economy will experience process innovation effort until period $t=\bar{t}$. From $t>\bar{t}$ onwards the economy will stop carrying out any type of innovation effort.

ii) If $\bar{t}(\sigma) \geq \underline{t}(\sigma)$, the economy will experience process innovation effort until period $t=\underline{t}$, and in $t=\underline{t}+1$ the economy will be able to switch to an equilibrium with product innovation effort.

Proposition 3 shows first that when parametric conditions lead to $\bar{t}(\sigma)<\underline{t}(\sigma)$, the economy will never manage to switch to an equilibrium with product innovation. Importantly, in these cases, process innovation and income growth will eventually come to a halt. This will happen in $t=\bar{t}$. From then on, the value of $R_{t}$ will remain constant at $\bar{t}$, implying in turn that incomes will also stay fixed thereafter, at the level $Y_{t}=1+\sigma \bar{t}$ for all $t \geq \bar{t}$.

\footnotetext{
${ }^{25}$ The fact that $\underline{R}_{1}$ decreases with $\sigma$ can be observed directly from the expression in (20); a formal proof that $\underline{R}_{2}$ decreases with $\sigma$ can be found in Appendix E.
} 
Conversely, when $\bar{t}(\sigma) \geq \underline{t}(\sigma)$, an equilibrium with product innovation effort will arise in $t=\underline{t}+1$. The economy will experience an initial phase of growth driven by process innovation effort until $t=\underline{t}$. As incomes rise during this phase, the (implicit) willingness to pay for the higher-quality version increases. Eventually, at $t=\underline{t}+1$ the willingness to pay for $q=1+\rho$ becomes high enough to turn product innovation effort more profitable than process innovation effort. At this point, the growth-regime switch can take place.

An important question to address is what turns the condition $\bar{t}(\sigma) \leq \underline{t}(\sigma)$ more likely to hold. Recall that $\bar{R}(\sigma)$ is increasing in $\sigma$, while $\underline{R}(\sigma)$ is decreasing in $\sigma$. In addition, from the expressions in (20) and (21), it follows that the threshold $\underline{R}(\sigma)$ also satisfies $\lim _{\sigma \rightarrow 0} \underline{R}(\sigma)=\infty$ and $\lim _{\sigma \rightarrow \infty} \underline{R}(\sigma)=0$, while from (12) we can observe that $\lim _{\sigma \rightarrow \infty} \bar{R}(\sigma)=\left(e^{\eta}-1\right)^{-1}>0$. As a result, given the way $\bar{t}(\sigma)$ and $\underline{t}(\sigma)$ are defined, there must always exist a value of $\sigma$ high enough to ensure that condition $\bar{t}(\sigma) \leq \underline{t}(\sigma)$ holds true. We state this result more formally in the following corollary.

Corollary 1 There exists a strictly positive and finite cut-off value, $\widehat{\sigma}>e^{\eta}-1$, such that when $\sigma>\widehat{\sigma}$, the condition $\bar{t}(\sigma) \leq \underline{t}(\sigma)$ holds true.

\subsection{From Product Innovation (Back) to Process Innovation}

In our model, process innovation effort exhibits an inherent tendency to come to a halt. For this reason, it becomes crucial that the switch to an equilibrium with product innovation effort takes place soon enough; otherwise the switch will simply end up not happening at all. Naturally, product innovation effort helps sustaining positive growth while it takes place. However, this is only one part of the positive effect that product innovation exerts on growth: product innovation effort may also boost the incentives to further undertake process innovation effort in future periods.

The underlying reason why the incentives to undertake process innovation effort exhibit an intrinsic decaying tendency rests on the decreasing marginal utility of consumption. As process innovations lead to an expansion of the physical production of the baseline quality version of the final good, the additional utility that individuals obtain from higher consumption levels of it declines, hurting in turn the profit derived from another round of process innovation. Product innovation effort works, however, on a rather distinct dimension: it leads to higher utility by each unit of physical consumption. Furthermore, the marginal utility of consumption declines more slowly for higher quality versions than for lower quality ones. Quality upgrading thus relaxes the depressing effect that decreasing marginal utility of consumption imposes on the incentives to further raise physical production via process innovation. 
In the sake of brevity, in this subsection we focus only on the case in which $\bar{t}(\sigma) \geq \underline{t}(\sigma)$ holds. This means that the growth path of the economy is driven by positive process innovation effort until period $t=\underline{t}$, with $R_{t}=t$ during that phase. Next, at $t=\underline{t}+1$, the economy is able to switch to an equilibrium with product innovation effort. This will allow the production of the quality version $q=1+\rho$ in $t=\underline{t}+1$, and also in all $t>\underline{t}+1$.

Consider now an economy in $t=\underline{t}+2$, right after an equilibrium with product innovation effort took place. Firms active in this period will inherit a technology that allows them to produce $(1+\sigma \underline{t}) /(1+\rho)$ units the quality version $q=1+\rho$ with one unit of labour. The question to address now is whether the individuals alive in $t=\underline{t}+2$ will choose to invest their spare time endowment in process innovation effort, or if they will prefer to consume it as leisure.

When a generic individual $i$ alive in $t=\underline{t}+2$ exerts process innovation effort, he will be able to sell his blueprint for a price

$$
\pi_{i, \underline{t}+2}^{p}=P_{\underline{t}+2} \frac{1+\sigma(1+\underline{t})}{1+\rho}-w_{\underline{t}+2}
$$

where,

$$
P_{\underline{t}+2}=(1+\rho) Y_{\underline{t}+2}^{\rho /(1+\rho)} \quad \text { and } \quad w_{\underline{t}+2}=P_{\underline{t}+2} \frac{1+\sigma \underline{t}}{1+\rho} .
$$

Hence, if $i$ exerts process innovation effort, his lifetime earnings will be given by

$$
Y_{i, \underline{t}+2}\left(\varepsilon_{i, p}=1\right)=Y_{\underline{t}+2}^{\rho /(1+\rho)}[1+\sigma(1+\underline{t})]
$$

On the other hand, if $i$ uses his spare time endowment as leisure, he will only obtain the wage $w_{\underline{t}+2}$. Thus,

$$
Y_{i, \underline{t}+2}\left(\varepsilon_{i, p}=0\right)=Y_{\underline{t}+2}^{\rho /(1+\rho)}(1+\sigma \underline{t}) .
$$

Comparing (23) and (24), leads finally to the following result:

Proposition 4 Consider an economy for which the condition $\bar{t}(\sigma) \geq \underline{t}(\sigma)$ is satisfied. Then, following an equilibrium with product innovation effort in $t=\underline{t}+1$, the individuals alive in $t=\underline{t}+2$ will exert process innovation effort in equilibrium (i.e., $\varepsilon_{\underline{t}+2, p}^{*}=1$ ), if and only if:

$$
(1+\rho)[\ln (1+\sigma \underline{t}+\sigma)-\ln (1+\sigma \underline{t})]>\eta
$$

To interpret Proposition 4, it proves insightful to compare condition (25) vis-a-vis (11). Recall that along a growth path with positive process innovation effort we have $R_{t}=t$. Given this, according to condition (11), an economy that managed to sustain process innovation effort until $t=\underline{t}$ would next need to satisfy 


$$
\ln (1+\sigma \underline{t}+\sigma)-\ln (1+\sigma \underline{t})>\eta
$$

in order to be able to keep sustaining further process innovation effort after period $\underline{t}$. The situation is slightly different for an economy that exhibited a growth path with process innovation effort until $\underline{t}$, and switched to an equilibrium with product innovation effort in $\underline{t}+1$. In this case, to be able to support further process innovation effort after period $\underline{t}+1$, the economy will need to satisfy (25). This condition is actually weaker than (26) since $\rho>0$. Hence, in our model, product innovation effort may also foster growth by reinvigorating the incentives to carry out further process innovation effort in future periods.

\subsection{Coordination Failures and Low-Quality Traps}

Proposition 2 showed that under certain parametric configurations our model exhibits multiple equilibria. In one equilibrium, individuals' expectations coordinate on $\varepsilon_{t, q}^{*}=1$. This is the equilibrium we studied in the previous two subsections, where product innovation keeps the economy on a positive growth path during $t$ (and, possibly, it also fosters future growth by regenerating the incentives for further process innovation after $t$ ). The other equilibrium is, instead, the result of a coordination failure: individuals expect no one to exert product innovation effort, which ends up curbing individuals' incentives to do so.

The possibility of coordination failures rests on the combined effect of a pecuniary and a nonpecuniary positive externality associated to exerting product innovation effort. The intuition behind the pecuniary externality is quite straightforward. As more individuals exert product innovation effort (instead of consuming leisure) the value of $Y_{t}$ increases. This in turn means that the firm selling the higher-quality version of the good can charge a higher price $\left(P_{t}\right)$ for it, which ultimately translates into a greater value of product innovation blueprints $\left(\pi_{t}^{q}\right)$.

The intuition for the non-pecuniary externality in more subtle. It relates to a higher probability of expansion in the set of available quality versions $\left(Q_{t}\right)$ as more individuals exert product innovation effort. Recall that only one blueprint $\left(s_{t}^{q}\right)$ in the set of feasible blueprints $\left(B_{t}^{q}\right)$ will turn out to be successful in generating quality upgrading. As consequence, the larger the mass of individuals who exert product innovation effort, the greater the probability that one of those individuals will generate the blueprint $s_{t}^{q}$. Individuals derive more utility from the higherquality version than from the baseline quality version. Hence, an increased probability that the higher-quality version will be marketed in period $t$ will indirectly raise as well the incentives for individuals to use their spare time endowment as product innovation effort. ${ }^{26}$

\footnotetext{
${ }^{26}$ While the pecuniary externality linked to product innovation effort has a similar flavour to those present in
} 


\section{$5 \quad$ Unbounded Quality Levels and Long-Run Growth}

So far we have studied an environment with only two levels of quality; i.e., $Q=\{1,1+\rho\}$. While this simplified framework is able to convey our main insights in terms of feedbacks between process and product innovation effort, it cannot generate dynamics with rising incomes in the long run. In particular, when $Q$ is bounded above, innovation and growth will eventually stop, no matter the parametric configuration of the model. ${ }^{27}$ This section extends the previous model by allowing an infinite number of quality levels. Interestingly, we show that in this case those economies that manage to switch to an equilibrium with quality upgrading in $t=\underline{t}+1$ (as described in Proposition 3) will turn out to be able to sustain positive growth forever.

Before moving on to show this result formally, it should be first straightforward to note that allowing an infinite number of quality levels will not alter any of our previous results for economies that fail to reach at some point an equilibrium with product innovation. In other words, if the parametric configuration of the model is such that $\bar{t}(\sigma)<\underline{t}(\sigma)$, the results in Proposition 3 will remain intact even when $Q$ is not bounded above. That is, the economy will experience process innovation effort until period $t=\bar{t}$, and it will stop carrying out any type of innovation effort after period $\bar{t}$.

For the rest of this section we will then focus on the case when $\bar{t}(\sigma) \geq \underline{t}(\sigma)$. As we have already seen, this economy will feature an equilibrium with process innovation until period $t=\underline{t}$, and it will switch to an equilibrium with product innovation in $t=\underline{t}+1 .^{28}$ The question to address now is two-fold: whether the economy will be able to sustain an equilibrium with some type of innovation effort in $t=\underline{t}+2$, and in case it is able to do so which type of innovation effort it will be. Naturally, if the economy experiences some type of innovation effort in $\underline{t}+2$, the very same question will arise again in $\underline{t}+3$, and so on and so forth.

The following lemma shows an important preliminary result regarding the income path in the long run when the set $Q$ comprises an infinite number of quality versions.

the Big Push literature [e.g., Murphy, Shleifer and Vishny (1989)], the non-pecuniary externality is conceptually very different from those studied before in the context of coordination failures and poverty traps. This externality is caused by an expansion in the consumption space when the economy experiences a product innovation, which in turn alters agents' marginal rate of substitution between leisure and commodity consumption in favour of the latter (thereby indirectly enhancing agents' incentives to undertake product innovation effort).

${ }^{27}$ See Appendix D for a description of how growth eventually stop in our previous version of the model with $Q=\{1,1+\rho\}$, even when an economy manages to switch to an equilibrium with product innovation effort at some point along the growth path.

${ }^{28}$ In the sake of brevity, in this section we disregard again the possibility that coordination failures may prevent an equilibrium with product innovation effort from taking place when this equilibrium actually exists. 
Lemma 5 When $Q=\{1,1+\rho, 1+2 \rho, \ldots\}$, economies that satisfy the condition $\bar{t}(\sigma) \geq \underline{t}(\sigma)$ will always be able to sustain an equilibrium with some type of innovation effort.

Lemma 5 essentially states that economies which are able to switch to an equilibrium with product innovation in period $\underline{t}+1$, will also be able sustain an equilibrium with positive innovation effort and income growth in all periods after $\underline{t}+1$. The reason behind this result is the following: if the non-deviation condition (16) holds in $\underline{t}+1$ when $R_{t-1}=\underline{t}$, then the analogous non-deviation conditions that would apply to a quality version $q>1+\rho$ in future periods will always hold true for any $R_{t-1} \geq \underline{t}$. This in turn means that, in any period $t \geq \underline{t}+2$, the action $\varepsilon_{i, q}=1$ will strictly dominate the action $\varepsilon_{i}=0$ when all the other individuals $j \neq i$ are choosing $\varepsilon_{j, q}=1$, ruling out the possibility that leisure consumption arises as a unique equilibrium in a period $t \geq \underline{t}+2$.

Lemma 5 addresses the question of whether an economy may sustain an equilibrium with some type of innovation effort in the periods that follow $t=\underline{t}+1$. We proceed to study now which type of innovation effort takes place in those periods. We first show that a growth path where only product innovation effort takes place in all $t>\underline{t}+1$ can never arise in equilibrium. Next, we show that a growth path along $t>\underline{t}+1$ that relies only on process innovation effort cannot take place in equilibrium either. Given the result in Lemma 5, we finally show that the growth path followed during the horizon $t \geq \underline{t}+1$ will display finite spells with product innovation, alternating with finite spells with process innovation.

Consider first the situation in which the only type of innovation effort undertaken during $t>\underline{t}+1$ is in product innovation. In this case, we would have $R_{t-1}=\underline{t}$ for all $t>\underline{t}+1$. In addition, the highest quality version available in $t$ (when $t>\underline{t}+1$ ) would be $q_{t}=1+(t-\underline{t}) \rho$. These results in turn imply that, when $\varepsilon_{t, q}=1$ for all $t>\underline{t}+1$, the income in a generic period $t>\underline{t}+1$ will be given by

$$
Y_{t}\left(\widetilde{\varepsilon}_{q, t>\underline{t}+1}\right)=(1+\sigma \underline{t})^{1+(t-\underline{t}) \rho}
$$

where we use $\widetilde{\varepsilon}_{q, t>\underline{t}+1}$ to denote the hypothetical path in which $\varepsilon_{t, q}=1$ for all $t>\underline{t}+1$. For this to be an equilibrium path no single individual alive in any period $t>\underline{t}+1$ would prefer to deviate from it to exerting process innovation effort. Notice that if a generic individual $i$ alive in $t>\underline{t}+1$ chose instead to set $\varepsilon_{i, t, p}=1$, his earnings would be

$$
Y_{t}\left(\varepsilon_{i, t, p}=1 \mid \widetilde{\varepsilon}_{q, t>\underline{t}+1}\right)=Y_{t}\left(\widetilde{\varepsilon}_{q, t>\underline{t}+1}\right)^{(t-1-\underline{t}) \rho /[1+(t-1-\underline{t}) \rho]}(1+\sigma \underline{t}+\sigma) .
$$

Comparing (27) and (28), we can observe that $Y_{t}\left(\widetilde{\varepsilon}_{q, t>\underline{t}+1}\right)>Y_{t}\left(\varepsilon_{i, t, p}=1 \mid \widetilde{\varepsilon}_{q, t>\underline{t}+1}\right)$ requires that $(1+\sigma \underline{t})^{1+(t-\underline{t}) \rho}>(1+\sigma \underline{t}+\sigma)^{1+[(t-1)-\underline{t}] \rho}$, which will fail to hold when $t$ becomes sufficiently large (i.e., when $t$ departs sufficiently from $\underline{t}$ ). 
Suppose now that during $t>\underline{t}+1$ all individuals use their spare time endowments as process innovation effort. Such a growth path would be characterised by $R_{t}=t-1$ and $q_{t-1}=1+\rho$, for all $t>\underline{t}+1$. The income in a generic period $t>\underline{t}+1$ will be thus given by

$$
Y_{t}\left(\widetilde{\varepsilon}_{p, t>\underline{t}+1}\right)=[1+\sigma(t-1)]^{1+\rho},
$$

where $\widetilde{\varepsilon}_{p, t>\underline{t}+1}$ denotes the hypothetical path in which $\varepsilon_{t, p}=1$ for all $t>\underline{t}+1$. If individual $i$ alive in $t>\underline{t}+1$ deviates to exerting product innovation effort (i.e., $\varepsilon_{i, t, q}=1$ ), he would obtain

$$
Y_{t}\left(\varepsilon_{i, t, q}=1 \widetilde{\varepsilon}_{p, t>\underline{t}+1}\right)=Y_{t}\left(\widetilde{\varepsilon}_{p, t>\underline{t}+1}\right)^{2 \rho /(1+2 \rho)}[1+\sigma(t-2)] .
$$

Now, comparing (29) and (30), it follows that $Y_{t}\left(\widetilde{\varepsilon}_{p, t>\underline{t}+1}\right)>Y_{t}\left(\varepsilon_{i, t, q}=1 \mid \widetilde{\varepsilon}_{p, t>\underline{t}+1}\right)$ requires $[1+\sigma(t-1)]^{1+\rho}>[1+\sigma(t-2)]^{1+2 \rho}$, which will also fail to hold when $t$ is large enough.

We can now present the main result of this section, describing the growth path followed by economies that manage to sustain positive growth in the long run.

Proposition 5 When $Q=\{1,1+\rho, 1+2 \rho, \ldots\}$, only those economies that satisfy the condition $\bar{t}(\sigma) \geq \underline{t}(\sigma)$ will be able to sustain an equilibrium growth path with positive growth in the long run. Along such a growth path, the economy will experience the following growth sequence:

1. There is an initial growth phase driven by process innovation effort starting in $t=1$ until period $t=\underline{t} \geq 1$

2. There is a second growth phase driven product innovation effort starting in $t=\underline{t}+1$, and lasting for a finite number of periods until period $\widehat{t} \geq \underline{t}+1$.

3. After $\widehat{t}$, the growth path exhibits finite spells of growth driven by process innovation effort, alternating with finite spells of growth driven by product innovation effort.

Proposition 5 shows that economies whose $\sigma$ turns out to be large enough to make the condition $\bar{t}(\sigma) \geq \underline{t}(\sigma)$ hold true (i.e., $\sigma>\widehat{\sigma}$ as defined in Corollary 1 ) will be able to exhibit positive income growth in the long run. The growth path of these economies is characterised by an initial phase driven by process innovation effort, followed by a sequence of finite spells of growth driven by product innovation effort and process innovation effort that alternate each other indefinitely. This result showcases the interplay between process and product innovations present in our model. On one side, the quantity expansion brought about by process innovations bolsters the incentives to start investing in quality-upgrading innovations. On the other side, the ensuing quality expansion stemming from product innovations relaxes the inherent tendency 
of profit prospects from further process innovations to decay. The alternation of equilibria with process and product innovation efforts exploits this feedback loop, and is thus instrumental to keeping income growth alive in the long run.

An interesting implication of Proposition 5 is that the growth path of an economy satisfying $\sigma>\widehat{\sigma}$ will display deterministic growth cycles. In particular, spells where growth rates slow down owing to the eroding effect of quantity expansion on marginal utility of consumption alternate with periods of higher growth rates when quality upgrading takes place. In turn, higher growth rates resulting from quality upgrading will reinvigorate growth rates from further quantity expansion. This dynamic mechanism is related to that one in Matsuyama (1999), which highlights the alternation of growth cycles driven by capital accumulation (to expand the stock of capital) and innovation activities (to expand the variety of capital goods). In Matsuyama (1999), the decreasing marginal productivity of a fixed variety of capital goods implies that expanding the variety of capital goods is necessary for long-run growth. In our model, cycles emerge from a different source of interaction: the complementarities of independently meaningful types of innovation effort, whose relative prominence shifts endogenously along the growth path. As such, our model yields novel insights regarding the importance of quality upgrading innovations vis-a-vis cost-cutting innovations as main growth drivers at different stages of development. ${ }^{29}$

As a final remark, it is worth noting that $\bar{t}(\sigma) \geq \underline{t}(\sigma)$ is a necessary and sufficient condition for an economy to exhibit sustained income growth. As a consequence, Proposition 5 entails the possibility of income divergence in the long run across different economies. In particular, those economies whose $\sigma$ lie below the cutoff value $\widehat{\sigma}$ in Corollary 1 will eventually fall trapped in an equilibrium without income growth. On the other hand, when $\sigma>\widehat{\sigma}$, income per head will be able to keep rising unboundedly at a positive rate in the long run.

\section{Concluding Remarks}

We presented a model where the combined effect of process and product innovations steer the economy along a growth path featuring both quantity and quality expansion. At early stages of development, when willingness to pay for quality upgrading is low, growth must be driven by the cost-cutting effect of process innovations. However, an economy cannot rely ex-

\footnotetext{
${ }^{29}$ Shleifer (1986) and Francois and Lloyd-Ellis (2003) also present models that feature deterministic growth cycles. In those models cycles are the result of the endogenous clustering of innovations in certain moments of time due to the presence of (positive) demand externalities.
} 
clusively on process innovations in order to achieve long-lasting growth, as their profits tend to decrease as physical production keeps expanding. Sustained growth necessitates that the economy becomes also able to generate product innovations as it moves along the development path. In addition, quality-upgrading innovations boost the incentives to keep expanding physical production. Therefore, while process innovations are necessary to turn product innovations sufficiently profitable, product innovations are able to regenerate profit prospects from further process innovations. This implicit feedback loop may keep growth alive in the long run.

Our model has restricted the consumption space to a very specific case: one single final good available in different quality versions, which are all perfect substitutes among each other. One important type of innovation effort that our model has then ruled out is that one that leads to a horizontal expansion in the set of final goods, as in Judd (1985), Romer (1990), and Grossman and Helpman (1991c, Ch.3), Young (1993). In principle, these types of innovations may also be able to keep growth alive in the long run. In particular, as profit prospects from cost-cutting innovations dwindle owing to decreasing marginal utility in a given good category, individuals may at some point find it worthwhile to introduce a completely new good category. This new final good would offer initially large profit prospects from process innovations, which would tend to diminish with subsequent rounds of it. We see this mechanism leading to a horizontal expansion of the set of consumption goods as complementary to the interplay between quantity and quality expansion studied by our model. Certainly, a model in which growth features a simultaneous expansion in quantity, quality and variety of consumption, with positive feedbacks between all three dimensions, could yield a more encompassing description of growth in mature economies, and we see this as an appealing avenue of future research.

Finally, our model studies the case of a closed economy in autarky. An interesting question that we cannot then address here is whether our framework, adapted to include open economies and trade, could possibly lead to some sort of international specialisation of innovation effort by type. In particular, in the presence of trade costs, it may be the case that process innovation effort tends move to middle-income economies, while richer economies specialise mainly in generating product innovations. Such result would be somehow reminiscent of the Linder's hypothesis of quality specialisation in trade, and could therefore provide an explanation of that theory originated from a fully-fledged endogenous growth model. 


\section{Appendix A: Proofs}

Proof of Lemma 1. An individual in $t$ will optimally set $\varepsilon_{t}^{*}=1$ iff the utility obtained from consuming $1+\sigma R_{t-1}+\sigma$ units of the baseline quality good is strictly greater than the utility derived from consuming $1+\sigma R_{t-1}$ units of it plus the utility of leisure, $\eta$. Using (9) and (10), together with the utility function (4) when $Q_{t}=\{1\}$, condition (11) obtains.

Proof of Lemma 2. We first notice that in any feasible equilibrium of our model, we will have that $[q x(q)]^{q} \geq q x(q)$, and hence we can focus only on that part of the utility function (4). ${ }^{30}$ Next, we carry out the proof in three separate steps.

Step 1) $P_{t}>(1+\rho) Y_{t}^{\rho /(1+\rho)}$ cannot hold in equilibrium.

Using (4) we can observe that the utility obtained by an individual alive in $t$ if he chooses to consume the version of the good with quality $q=1+\rho$ is given by:

$$
U_{t}(q=1+\rho)=\ln \left[(1+\rho) \frac{Y_{t}}{P_{t}}\right]^{1+\rho}
$$

Instead, if he chooses to consume the baseline quality version, he would obtain:

$$
U_{t}(q=1)=\ln \left(Y_{t}\right)
$$

Hence, comparing (31) and (32), we can observe that $P_{t}>(1+\rho) Y_{t}^{\rho /(1+\rho)}$ implies $U_{t}(q=$ $1+\rho)<U_{t}(q=1)$, and therefore no one would consume the higher-quality version.

Step 2) $P_{t}<(1+\rho) Y_{t}^{\rho /(1+\rho)}$ cannot hold in equilibrium.

Suppose in equilibrium $P_{t}=\widetilde{P}_{t}<(1+\rho) Y_{t}^{\rho /(1+\rho)}$. Since an equilibrium must also necessarily satisfy the zero profit condition, it must then be the case that product innovators are being paid

$$
\widetilde{\pi}_{t}=\widetilde{P}_{t} \frac{1+\sigma R_{t-1}}{1+\rho}-\left(1+\sigma R_{t-1}\right)
$$

for their blueprints. Suppose now some firm decides to offer product innovators $\widehat{\pi}_{t}$ for their blueprints, where

$$
\widehat{\pi}_{t} \equiv\left(\widetilde{P}_{t}+\widehat{\varepsilon}\right) \frac{1+\sigma R_{t-1}}{1+\rho}-\left(1+\sigma R_{t-1}\right), \quad \text { and } \quad \widehat{\varepsilon}>0
$$

This firm would then attract all product innovation blueprints created in $t$. Furthermore, this firm could charge a price $P_{t}^{\prime} \equiv \widetilde{P}_{t}+\varepsilon^{\prime}<(1+\rho) Y_{t}^{\rho /(1+\rho)}$, where $\varepsilon^{\prime}>\widehat{\varepsilon}>0$, for the higher-quality version of the final good, obtaining positive (expected) profits. As a consequence, a situation

\footnotetext{
${ }^{30}$ For a formal proof of this result, see Appendix E.
} 
where a firm charges a price $P_{t}<(1+\rho) Y_{t}^{\rho /(1+\rho)}$ for the higher-quality version while it also satisfies the zero profit condition cannot arise in equilibrium.

Step 3) Using again (31) and (32), we can first observe that when $P_{t}=(1+\rho) Y_{t}^{\rho /(1+\rho)}$ individuals alive in $t$ are indifferent between the baseline quality version and the higher-quality version. Moreover, when (13) holds, there exist no profitable deviation to any firm. In particular, in order to outcompete a firm whose strategy is characterised by (14) and (13), another firm should either offer the higher-quality version for a lower price or, alternatively, offer product innovators a higher payment for their blueprints while keeping the price of the higher quality version fixed (since $P_{t}>(1+\rho) Y_{t}^{\rho /(1+\rho)}$ cannot hold in equilibrium, as shown before in Step 1). Both deviations, however, lead to a loss.

Proof of Proposition 1. The proof follows immediately from the derivations in the main text, together with the fact that (1) implies that after a sequence of $t$ consecutive periods featuring an equilibrium with positive process innovation effort we have that $R_{t}=t$.

Proof of Lemma 3. Using (13), we obtain that when individuals alive in $t$ exert product innovation effort:

$$
Y_{t}=P_{t} \frac{1+\sigma R_{t-1}}{1+\rho}
$$

Replacing (33) into (14) yields

$$
P_{t}=(1+\rho)\left(P_{t} \frac{1+\sigma R_{t-1}}{1+\rho}\right)^{\frac{\rho}{1+\rho}}
$$

from where we may solve for $P_{t}$ and obtain:

$$
P_{t}=(1+\rho)\left(1+\sigma R_{t-1}\right)^{\rho} .
$$

Lastly, plugging (34) into (33) yields (15).

Proof of Lemma 4. Part $i$ ). First of all, notice that equation (15) implies that when the entire cohort alive in $t$ undertake product innovation, $Y_{t}=\left(1+\sigma R_{t-1}\right)^{1+\rho}$. In this situation, the level of utility achieved by any generic individual $i$ alive in $t$ is given by

$$
U_{i, t}\left(\varepsilon_{i, t, q}=1 \mid \varepsilon_{t, q}=1\right)=\ln \left[(1+\rho) \frac{\left(1+\sigma R_{t-1}\right)^{1+\rho}}{P_{t}}\right]^{1+\rho} .
$$

Using the expression in (14), together with $Y_{t}=\left(1+\sigma R_{t-1}\right)^{1+\rho},(35)$ yields:

$$
U_{i, t}\left(\varepsilon_{i, t, q}=1 \mid \varepsilon_{t, q}=1\right)=(1+\rho) \ln \left(1+\sigma R_{t-1}\right)
$$


Suppose now this generic individual $i$ alive in $t$ would deviate from $\varepsilon_{i, t, q}=1$ to setting $\varepsilon_{i, t}=0$. In this case, $Y_{i, t}\left(\varepsilon_{i, t}=0\right)=w_{t}=1+\sigma R_{t-1}$. Notice now that the price (14) leaves indifferent an individual with $Y_{t}=\left(1+\sigma R_{t-1}\right)^{1+\rho}$ between the two versions of the consumption good. Since, $1+\sigma R_{t-1}<\left(1+\sigma R_{t-1}\right)^{1+\rho}$, it must then be the case that, if setting $\varepsilon_{i, t}=0$, individual $i$ will then strictly prefer to consume the baseline quality rather than (the more expensive) higher-quality version. Moreover, when $w_{t}=1+\sigma R_{t-1}$, there will always be a firm willing to offer the baseline quality version (i.e., $q=1$ ), as it would break even by doing so. Hence, when a generic individual $i$ alive in $t$ sets $\varepsilon_{i, t}=0$, within a context where the rest are setting $\varepsilon_{t, q}=1, i$ achieves

$$
U_{i, t}\left(\varepsilon_{i, t}=0 \mid \varepsilon_{t, q}=1\right)=\ln \left(1+\sigma R_{t-1}\right)+\eta
$$

Finally, comparing (36) and (37), condition (16) ensures that $U_{i, t}\left(\varepsilon_{i, t, q}=1 \mid \varepsilon_{t, q}=1\right)>$ $U_{i, t}\left(\varepsilon_{i, t}=0 \mid \varepsilon_{t, q}=1\right)$, completing the proof.

Part $i i)$ Since both $\varepsilon_{i, t, q}=1$ and $\varepsilon_{i, t, p}=1$ entail the leisure loss of $\eta$, a necessary and sufficient condition for $U_{i, t}\left(\varepsilon_{i, t, p}=1 \mid \varepsilon_{t, q}=1\right)<U_{i, t}\left(\varepsilon_{i, t, q}=1 \mid \varepsilon_{t, q}=1\right)$ will be that $Y_{i, t}\left(\varepsilon_{i, t, p}=\right.$ $1)<Y_{i, t}\left(\varepsilon_{i, t, q}=1\right)$. Using then (9) and (15), condition (17) immediately obtains.

Proof of Proposition 2. Part $i$ ) The proof that when (16) and (17) hold there exists an equilibrium in $t$ with $\varepsilon_{t, q}^{*}$ follows directly from Lemma 4.

Part ii) We prove this part of the proposition in three separate steps.

Step 1) When condition (17) holds, an equilibrium with $\varepsilon_{t, p}^{*}=1$ does not exist.

Proof. Using (14) and (13), we can observe that a necessary condition for an equilibrium with $\varepsilon_{t, p}^{*}=1$ to exist is that: $Y_{t}^{(1+\rho) / \rho}\left(1+\sigma R_{t-1}\right)-\left(1+\sigma R_{t-1}\right)<\sigma$. This leads to the following expression:

$$
Y_{t}<\left(\frac{1+\sigma+\sigma R_{t-1}}{1+\sigma R_{t-1}}\right)^{\frac{1+\rho}{\rho}} .
$$

Consider then the case when all the individuals alive in $t$ set $\varepsilon_{t, p}=1$. In this situation $Y_{t}$ is given by (9). Plugging this value into the LHS of (38) leads after some simple algebra to $\left(1+\sigma+\sigma R_{t-1}\right)>\left(1+\sigma R_{t-1}\right)^{1+\rho}$, contradicting $(17)$.

Step 2) When condition (17) holds and condition (18) does not hold, an equilibrium with $\varepsilon_{t}^{*}=0$ does not exist.

Proof. Notice first that (18) not holding means that (11) holds true. Therefore, when (18) fails to hold no individual $i$ alive in $t$ would thus set $\varepsilon_{i, t}=0$ in equilibrium. Moreover, the fact that (17) holds in turn implies that the unique equilibrium in this case must feature $\varepsilon_{t, q}^{*}=1$. 
Step 3) When, alongside (16) and (17), also both (18) and (19) hold true, an equilibrium with $\varepsilon_{t}^{*}=0$ also exists.

When all the individuals alive in $t$ set $\varepsilon_{t}=0$, the expression in (10) applies, and thus $Y_{t}=1+\sigma R_{t-1}$. In this situation, if some generic individual alive in $t$ deviates to exerting product innovation effort, the price of the higher-quality version would be $P_{t}=(1+\rho)\left(1+\sigma R_{t-1}\right)^{\rho /(1+\rho)}$, and a product innovation blueprint would sell for $\pi_{i, t}^{q}=\left(1+\sigma R_{t-1}\right)^{(1+2 \rho) /(1+\rho)}-\left(1+\sigma R_{t-1}\right)$. As a result, by deviating to exerting product innovation, individual $i$ would have as lifetime income: $Y_{i, t}=\left(1+\sigma R_{t-1}\right)^{(1+2 \rho) /(1+\rho)}$. Notice now that since individual $i$ has measure zero, after his unilateral deviation to $\varepsilon_{i, t, q}=1$, the probability that he ends up generating the successful product innovation blueprint (i.e., $s_{t}^{q}$ ) is actually zero. Therefore, when individual $i$ is contemplating the possibility to deviate unilaterally to $\varepsilon_{i, t, q}=1$ (from a situation where all individuals alive in $t$ set $\varepsilon_{t}=0$ ), he is also aware that (almost surely) he will not end up generating $s_{t}^{q}$, and thus the only version that will be offered by firms is the baseline quality version, $q=1$. As a result, the utility that individual $i$ expects to obtain should he deviate unilaterally to $\varepsilon_{i, t, q}=1$ is given by:

$$
U_{i, t}\left(\varepsilon_{i, t, q}=1 \mid \varepsilon_{t}=0\right)=\ln \left(1+\sigma R_{t-1}\right)^{(1+2 \rho) /(1+\rho)} .
$$

On the other hand, by sticking to $\varepsilon_{i, t}=0$, individual $i$ would obtain:

$$
U_{i, t}\left(\varepsilon_{i, t}=0 \mid \varepsilon_{t}=0\right)=\ln \left(1+\sigma R_{t-1}\right)+\eta
$$

An equilibrium where $\varepsilon_{t}^{*}=0$ will exist if $U_{i, t}\left(\varepsilon_{i, t, q}=1 \mid \varepsilon_{t}=0\right) \leq U_{i, t}\left(\varepsilon_{i, t}=0 \mid \varepsilon_{t}=0\right)$. Therefore, using (39) and (40), we can obtain (19). This completes the proof that when both (18) and (19) are verified by an economy that also satisfies (16) and (17), then two equilibria exist (among the class of symmetric Nash equilibria in pure strategies): $\varepsilon_{t, q}^{*}=1$ and $\varepsilon_{t}^{*}=0$.

Proof of Proposition 3. Part $i$ ) From Proposition 1, it follows that the economy will keep growing through process innovation effort until $t=\bar{t}(\sigma)$, and reach a level of $R_{\bar{t}}=\bar{t}(\sigma)$ in that period. Consider now what happens in $t=\bar{t}(\sigma)+1$. We know from Proposition 1 that no individual alive in $t=\bar{t}(\sigma)+1$ will invest in process innovation. Also, the fact that $\underline{t}(\sigma)>\bar{t}(\sigma)$ means that $\bar{t}(\sigma) \leq \underline{t}(\sigma)-1$. Furthermore, from Definition 2 , it follows that $\underline{R}(\sigma)>\underline{t}(\sigma)-1$. Therefore, $\bar{t}(\sigma)<\underline{R}(\sigma)$, in turn implying that no individual alive in $t=\bar{t}(\sigma)+1$ will invest in product innovation either. Since individuals will then consume their spare time endowment as leisure in $t=\bar{t}(\sigma)+1$, the same situation will repeat itself in $t=\bar{t}(\sigma)+2$, and thereafter.

Part ii) Given the results in Proposition 1, we can observe that the economy will keep growing through process innovation effort until $t=\underline{t}(\sigma)$, and reach a level of $R_{\underline{t}}=\underline{t}(\sigma)$ in 
that period. Consider now what happens in period $t=\underline{t}(\sigma)+1$. Using again Definition $2, \underline{t}(\sigma)>\underline{R}(\sigma)$. Therefore, the conditions in Lemma 4 must hold true in $t=\underline{t}(\sigma)+1$, and the economy will therefore exhibit an equilibrium with product innovation effort in that period. Finally, owing to Proposition 2, in this situation the economy cannot possibly exhibit an equilibrium in $t=\underline{t}(\sigma)+1$ with process innovation effort, which completes the proof.

Proof of Proposition 4. From Assumption 2, we can observe that firms active in $t=\underline{t}+2$ will inherit a technology that will allow them to produce $(1+\sigma \underline{t}) /(1+\rho)$ units of the quality version $q=1+\rho$ with one unit of labour. Letting $P_{\underline{t}+2}$ denote the price of the quality version $q=1+\rho$ in period $t=\underline{t}+2$, it then follows that the equilibrium wage in that period will be $w_{\underline{t}+2}=P_{\underline{t}+2}(1+\sigma \underline{t}) /(1+\rho)$, which using the result in (14) leads to:

$$
w_{\underline{t}+2}=Y_{\underline{t}+2}^{\rho /(1+\rho)}(1+\sigma \underline{t}) .
$$

Notice now that since $Y_{\underline{t}+2}^{\rho /(1+\rho)}>1$, no firm active in $t=\underline{t}+2$ will, in equilibrium, offer the baseline quality version (if one of these firms did so, it would make a loss). As a result, in $t=\underline{t}+2$ the only quality version that will be actively offered in the market is $q=1+\rho$.

Consider now the effect of a process innovation in period $t=\underline{t}+2$. This would allow the firm that implements the process innovation to produce $(1+\sigma \underline{t}+\sigma) /(1+\rho)$ units of the quality version $q=1+\rho$ with one unit of labour. As a consequence, process innovation blueprints will command a price:

$$
\pi_{\underline{t}+2}^{p}=Y_{\underline{t}+2}^{\rho /(1+\rho)} \sigma .
$$

Using (41) and (42), we can then obtain for a generic individual $i$ alive in period $t=\underline{t}+2$ the following expressions:

$$
\begin{aligned}
& Y_{i, \underline{t}+2}\left(\varepsilon_{i, \underline{t}+2}^{p}=1\right)=Y_{\underline{t}+2}^{\rho /(1+\rho)}(1+\sigma \underline{t}+\sigma), \\
& Y_{i, \underline{t}+2}\left(\varepsilon_{i, \underline{t}+2}^{p}=0\right)=Y_{\underline{t}+2}^{\rho /(1+\rho)}(1+\sigma \underline{t}) .
\end{aligned}
$$

Finally, using (43), (44) and the utility function (4), bearing in mind $P_{\underline{t}+2}=(1+\rho) Y_{\underline{t}+2}^{\rho /(1+\rho)}$, we can observe that individuals in $t=\underline{t}+2$ will set $\varepsilon_{\underline{t}+2}^{p}=1$ if and only if (25) holds true.

Proof of Lemma 5. We carry out this proof by showing that when $\bar{t}(\sigma) \geq \underline{t}(\sigma)$ holds, in a context where the set $Q$ comprises an infinite number of quality versions, then for any generic individual $i$ alive in $t>\underline{t}$ the action $\varepsilon_{i, t, q}=1$ strictly dominates the action $\varepsilon_{i, t}=0$, when all other individuals $j \neq i$ alive in $t$ are choosing $\varepsilon_{j, t, q}=1$.

Step 1. Period $t=\underline{t}+1$ : The fact that when $\bar{t}(\sigma) \geq \underline{t}(\sigma)$ holds, $\varepsilon_{i, t, q}=1$ strictly dominates the 
action $\varepsilon_{i, t}=0$ when all other individuals $j \neq i$ alive in $t$ are choosing $\varepsilon_{j, t, q}=1$ follows directly from Proposition 3.

Step 2. Generalisation of Lemma 2 when $Q$ is unbounded above: When we let $Q=\{1,1+\rho, 1+$ $2 \rho, \ldots\}$, it follows that if a firm wishes to purchase the product innovation designed by a generic individual $i$ alive in period $t$, it will have to pay him:

$$
\pi_{i, t}^{q}=P_{t}\left(q_{t}\right) \frac{1+\sigma R_{t-1}}{q_{t}}-w_{t}
$$

where $P_{t}\left(q_{t}\right)$ is the price of the (newly designed) quality version $q_{t} \in Q$. To compute the equilibrium value of $P_{t}\left(q_{t}\right)$, notice that, based on (4), this will follow from the condition

$$
\ln \left(q_{t} \frac{Y_{t}}{P_{t}\left(q_{t}\right)}\right)^{q_{t}} \geq \ln \left(Y_{t}\right),
$$

from where we can obtain

$$
P_{t}\left(q_{t}\right)=q_{t} Y_{t}^{\left(q_{t}-1\right) / q_{t}}
$$

when (46) holds with equality. Lastly, the fact that all firms active in $t$ inherit a technology that allows producing $\left(1+\sigma R_{t-1}\right) / q_{t-1}$ units of the quality version $q_{t-1} \in Q$ with one unit of labour in turn implies that:

$$
w_{t}=P_{t}\left(q_{t-1}\right) \frac{1+\sigma R_{t-1}}{q_{t-1}}=Y_{t}^{\left(q_{t-1}-1\right) / q_{t-1}}\left(1+\sigma R_{t-1}\right)
$$

where $q_{t-1}=q_{t}-\rho$ when all individuals alive in $t$ exert product innovation effort.

Step 3. Generalisation of Lemma 3 when $Q$ is unbounded above: If all individuals alive in $t$ set $\varepsilon_{t, q}=1$, using (45), (47) and (48), we obtain:

$$
Y_{t}\left(\varepsilon_{t, q}=1\right)=\left(1+\sigma R_{t-1}\right)^{q_{t}}
$$

Step 4. Periods $t \geq \underline{t}+2$ : Due to Proposition 3, when $\bar{t}(\sigma) \geq \underline{t}(\sigma)$ holds, we must have that $R_{t-1} \geq \underline{t}$ and $q_{t-1} \geq 1+\rho$. Suppose also that all individuals set $\varepsilon_{t, q}=1$ in each period $t \geq \underline{t}+2$. Then, using (49), it follows that

$$
Y_{t}\left(\varepsilon_{t, q}=1\right)=[1+\sigma(\underline{t}+\delta)]^{q_{t}}
$$

where $\delta \geq 0$. Using next the utility function (4), together with (50) and (47), we may obtain:

$$
U_{i, t}\left(\varepsilon_{i, t, q}=1 \mid \varepsilon_{t, q}=1\right)=q_{t} \ln [1+\sigma(\underline{t}+\delta)],
$$


which denotes the level of utility achieved by a generic individual $i$ alive in $t \geq \underline{t}+2$ when he sticks to the choice $\varepsilon_{i, t, q}=1$, given that all other individuals are choosing $\varepsilon_{t, q}=1$. On the other hand, if in such same circumstance individual $i$ deviates to $\varepsilon_{i, t}=0$, he will achieve:

$$
U_{i, t}\left(\varepsilon_{i, t}=0 \mid \varepsilon_{t, q}=1\right)=q_{t-1} \ln [1+\sigma(\underline{t}+\delta)]+\eta=\left(q_{t}-\rho\right) \ln [1+\sigma(\underline{t}+\delta)]+\eta .
$$

Comparing (51) and (52), we obtain:

$$
U_{i, t}\left(\varepsilon_{i, t, q}=1 \mid \varepsilon_{t, q}=1\right)>U_{i, t}\left(\varepsilon_{i, t}=0 \mid \varepsilon_{t, q}=1\right) \quad \Longleftrightarrow \quad \rho \ln [1+\sigma(\underline{t}+\delta)]>\eta
$$

Finally, since $\delta \geq 0$, it immediately follows that when condition (16) holds in period $t=\underline{t}+1$ (which is the period when $R_{t-1}=\underline{t}$ ), then condition (53) will hold true in any period $t \geq \underline{t}+2$. Bearing in mind that $\rho \ln (1+\sigma \underline{t})>\eta$ is a necessary condition for $\bar{t}(\sigma) \geq \underline{t}(\sigma)$ to hold, this last step completes the proof that the action $\varepsilon_{i, t, q}=1$ strictly dominates $\varepsilon_{i, t}=0$ when all other individuals alive in $t$ set $\varepsilon_{t, q}=1$ in any generic period $t \geq \underline{t}+2$.

\section{Proof of Proposition 5.}

Part 1. The fact that there is an initial growth phase, between $t=1$ and $t=t \geq 1$ driven by process innovation is already proven in Proposition 3.

Part 2. The fact that there is a second growth phase starting in $t=\underline{t}+1$ that is driven by product innovation effort also follows directly from Proposition 3. Next, the fact that this growth phase lasts for a finite number of periods (i.e., it lasts until $t=\widehat{t} \geq \underline{t}+1$ ) follows from equations (27) and (28), together with the ensuing discussion in the main text.

Part 3. Lastly, to prove that after $t=\widehat{t}$ the economy will be able to sustain positive growth forever by alternating finite spells where the equilibrium features process innovation effort with finite spells where the equilibrium features product innovation effort, we proceed by contradiction, while bearing in mind the result in Lemma 5.

Consider first the case of a hypothetical economy that for all periods $t \geq t^{\prime}$ features process innovation effort in equilibrium, where we let $t^{\prime}>\widehat{t}$. Such a growth path would be characterised by $R_{t}=t-\left(q_{t^{\prime}-1}-1\right) / \rho$ and $q_{t}=q_{t^{\prime}-1}$, for all $t \geq t^{\prime}$. The income in a generic period $t \geq t^{\prime}$ will be thus given by

$$
Y_{t}\left(\widetilde{\varepsilon}_{p, t \geq t^{\prime}}\right)=\left\{1+\sigma\left[t-\left(q_{t^{\prime}-1}-1\right) / \rho\right]\right\}^{q_{t^{\prime}-1}},
$$

where $\widetilde{\varepsilon}_{p, t \geq t^{\prime}}$ denotes the hypothetical growth path in which $\varepsilon_{t, p}=1$ for all $t \geq t^{\prime}$. If a generic individual $i$ alive in $t \geq t^{\prime}$ deviates to exerting product innovation effort (i.e., $\varepsilon_{i, t, q}=1$ ), he will obtain

$$
Y_{t}\left(\varepsilon_{i, t, q}=1 \mid \widetilde{\varepsilon}_{p, t \geq t^{\prime}}\right)=Y_{t}\left(\widetilde{\varepsilon}_{p, t \geq t^{\prime}}\right)^{\left(q_{t^{\prime}-1}+\rho-1\right) /\left(q_{t^{\prime}-1}+\rho\right)}\left\{1+\sigma\left[t-1-\left(q_{t^{\prime}-1}-1\right) / \rho\right]\right\} .
$$


Now, comparing (54) and (55), it follows that $Y_{t}\left(\widetilde{\varepsilon}_{p, t \geq t^{\prime}}\right)>Y_{t}\left(\varepsilon_{i, t, q}=1 \mid \widetilde{\varepsilon}_{p, t \geq t^{\prime}}\right)$ requires

$$
\left\{1+\sigma\left[t-\left(q_{t^{\prime}-1}-1\right) / \rho\right]\right\}^{q_{t^{\prime}-1}}>\left\{1+\sigma\left[t-1-\left(q_{t^{\prime}-1}-1\right) / \rho\right]\right\}^{q_{t^{\prime}-1}+\rho}
$$

which will fail to hold when $t$ becomes sufficiently large. As a consequence, the economy cannot possibly sustain an equilibrium growth path where individuals exert process innovation effort during an infinitely long sequence of consecutive periods.

Consider next the case of a hypothetical economy that for all periods $t \geq t^{\prime}$ features product innovation effort in equilibrium, where again we let $t^{\prime}>\widehat{t}$. Such a growth path would be characterised by $R_{t-1}=\left(t^{\prime}-1\right)-\left(q_{t^{\prime}-1}-1\right) / \rho$ and $q_{t}=q_{t^{\prime}-1}+\left(t-t^{\prime}+1\right) \rho$, for all $t \geq t^{\prime}$. These results in turn imply that the income in a generic period $t \geq t^{\prime}$ will be given by

$$
Y_{t}\left(\widetilde{\varepsilon}_{q, t \geq t^{\prime}}\right)=\left\{1+\sigma\left[\left(t^{\prime}-1\right)-\left(q_{t^{\prime}-1}-1\right) / \rho\right]\right\}^{q_{t^{\prime}-1}+\left(t-t^{\prime}+1\right) \rho},
$$

where we use $\widetilde{\varepsilon}_{q, t \geq t^{\prime}}$ to denote the hypothetical path in which $\varepsilon_{t, q}=1$ for all $t \geq t^{\prime}$. If a generic individual $i$ alive in $t \geq t^{\prime}$ deviates to process innovation effort (i.e., $\varepsilon_{i, t, p}=1$ ), he will get

$$
Y_{t}\left(\varepsilon_{i, t, p}=1 \mid \widetilde{\varepsilon}_{q, t \geq t^{\prime}}\right)=Y_{t}\left(\widetilde{\varepsilon}_{q, t \geq t^{\prime}}\right)^{\left[q_{t^{\prime}-1}+\left(t-t^{\prime}\right) \rho-1\right] /\left[q_{t^{\prime}-1}+\left(t-t^{\prime}\right) \rho\right]}\left\{1+\sigma\left[t^{\prime}-\left(q_{t^{\prime}-1}-1\right) / \rho\right]\right\} .
$$

Now, comparing (56) and (57), it follows that $Y_{t}\left(\widetilde{\varepsilon}_{q, t \geq t^{\prime}}\right)>Y_{t}\left(\varepsilon_{i, t, p}=1 \mid \widetilde{\varepsilon}_{q, t \geq t^{\prime}}\right)$ requires

$$
\left\{1+\sigma\left[\left(t^{\prime}-1\right)-\left(q_{t^{\prime}-1}-1\right) / \rho\right]\right\}^{q_{t^{\prime}-1}+\left(t-t^{\prime}+1\right) \rho}>\left\{1+\sigma\left[t^{\prime}-\left(q_{t^{\prime}-1}-1\right) / \rho\right]\right\}^{q_{t^{\prime}-1}+\left(t-t^{\prime}\right) \rho}
$$

which will fail to hold when $t$ becomes sufficiently large. As a result, the economy cannot possibly sustain an equilibrium growth path where individuals exert product innovation effort during an infinitely long sequence of consecutive periods.

The previous two contradictions imply thus that there cannot exist an equilibrium growth path featuring either infinitely long spells of process innovation effort or infinitely long spells of product innovation effort. Lemma 5 stipulates that an economy satisfying the condition $\bar{t}(\sigma) \geq \underline{t}(\sigma)$ is always able to sustain an equilibrium with some type of innovation effort. Hence, it must be the case that the growth path followed by an economy satisfying $\bar{t}(\sigma) \geq \underline{t}(\sigma)$ will exhibit finite spells where individuals exert process innovation effort in equilibrium, alternating with finite spells where they exert product innovation effort in equilibrium. 


\section{Appendix B: Robustness Checks to the Correlations in Table 1}

The correlations displayed in Table 1 should only be taken as motivational evidence for our theory and model, and by no means we intend to present them as showing a causal effect of any sort. Nevertheless, it is important to show that these simple correlations are robust, and at the same time that they do not simply capture other country-level variables correlated with GDP per head. Here we provide some of these robustness checks.

Columns (1) - (3) of Table B.1 show the results of our previous regressions in columns (2) - (4) of Table 1 when using the logarithm of GDP per head, instead of the level. As we can readily see, this has essentially no qualitative effect on our previous results.

Next, recall that column (2) of Table 1 considered only those firms that have introduced process innovations, while column (3) considered only those firms that have introduced product innovations. However, some of the firms used for column (2) have also introduced product innovations, while some of the firms used for column (3) have also introduced process innovations. Columns (4) - (6) of Table B.1 show the results of our previous columns (2) - (4) of Table 1 with the following modification: $i$ ) in column (4) we consider only those firms that have introduced process innovations but have not introduced product innovations; $i i)$ in column (5) we consider only those firms that have introduced product innovations but have not introduced process innovations. The results follow a similar pattern as those in Table 1, but are even more pronounced than before (in fact, the correlation between GDP per head and the ratio of firms doing only process innovation and not doing product innovation, becomes now insignificant).

Table B.2 introduces in columns (1) - (3) total GDP as an additional independent variable. This would control for the presence of an aggregate size effect of the home market, which could differently affect investment in process and in product innovation. As it can be readily observed, all the correlations previously presented in Table 1 remain essentially intact, and the coefficient associated to total GDP is never significantly different from zero.

Finally, the results in Table 1 could alternatively be driven by a supply-side mechanism, rather than by our proposed income-dependent demand for quality upgrading. One such supplyside mechanism could be the result of disparities in the endowments of skilled labour across countries (for instance, if the stock of human capital could be more important for the generation of product innovations than for process innovations), since skilled labour endowments tend to correlate positively with GDP per capita. In order to see whether such type of supply-side mechanism is the one behind the correlations in Table 1, we also include in columns (4) - (6) 
Table B.1

\begin{tabular}{|c|c|c|c|c|c|c|}
\hline \multicolumn{7}{|c|}{ Dependent Variable } \\
\hline & $\begin{array}{l}\text { ratio firms doing } \\
\text { proc. innovation } \\
\end{array}$ & $\begin{array}{c}\text { ratio of firms } \\
\text { prod. innovation } \\
\end{array}$ & $\begin{array}{l}\text { ratio of prod. } \\
\text { to proc. innov. } \\
\end{array}$ & $\begin{array}{c}\text { ratio firms doing } \\
\text { ONLY process innov. }\end{array}$ & $\begin{array}{c}\text { ratio firms doing } \\
\text { ONLY product innov. }\end{array}$ & $\begin{array}{l}\text { ratio of ONLY prod. } \\
\text { to ONLY proc. innov. }\end{array}$ \\
\hline Log GDP per head & $\begin{array}{l}0.072 * * \\
(0.026)\end{array}$ & $\begin{array}{l}0.112 * * * \\
(0.024)\end{array}$ & $\begin{array}{l}0.150 * * \\
(0.073)\end{array}$ & & & \\
\hline GDP per head & & & & $\begin{array}{c}0.004 \\
(0.005)\end{array}$ & $\begin{array}{c}0.024 * * * \\
(0.004)\end{array}$ & $\begin{array}{l}0.272 * * * \\
(0.074)\end{array}$ \\
\hline R-squared & 0.21 & 0.44 & 0.13 & 0.03 & 0.55 & 0.33 \\
\hline Number countries & 30 & 30 & 30 & 30 & 30 & 30 \\
\hline
\end{tabular}

Table B.2

\begin{tabular}{|c|c|c|c|c|c|c|c|c|c|}
\hline \multicolumn{10}{|c|}{ Dependent Variable } \\
\hline Total GDP & $\begin{array}{l}0.00000246 \\
(0.0000188)\end{array}$ & $\begin{array}{c}0.0000131 \\
(0.0000166)\end{array}$ & $\begin{array}{c}0.0000323 \\
(0.0000466)\end{array}$ & $\begin{array}{l}0.00000158 \\
(0.0000186)\end{array}$ & $\begin{array}{c}0.0000131 \\
(0.0000169)\end{array}$ & $\begin{array}{r}0.000035 \\
(0.000045)\end{array}$ & $\begin{array}{l}0.00000519 \\
(0.0000189)\end{array}$ & $\begin{array}{c}0.0000102 \\
(0.0000176)\end{array}$ & $\begin{array}{c}0.0000451 \\
(0.0000472)\end{array}$ \\
\hline Financial Depth & & & & & & & $\begin{array}{c}0.057 \\
(0.040)\end{array}$ & $\begin{array}{c}0.024 \\
(0.037)\end{array}$ & $\begin{array}{l}-0.0845 \\
(0.0996)\end{array}$ \\
\hline R-squared & 0.12 & 0.43 & 0.25 & 0.17 & 0.43 & 0.32 & 0.23 & 0.44 & 0.34 \\
\hline Number countries & 30 & 30 & 30 & 30 & 30 & 30 & 30 & 30 & 30 \\
\hline
\end{tabular}

the average educational attainment in each country in the sample. As we can see, none of the previous results in Table 1 are significantly altered by this. Another possible supply-side mechanism could be to do with different levels of financial development across economies. ${ }^{31}$ In order to assess whether this is the reason behind the correlation patterns in Table 1, columns (6) - (9) of Table B.2 introduce a measure of financial depth (the ratio of total private credit by banks over GDP) as additional regressor. Once again, the main qualitative patterns exhibited by Table 1 remain unaltered, while the correlation coefficient associated to the ratio of firms doing process innovation becomes insignificant.

\footnotetext{
${ }^{31}$ See Crino and Ogliari (2017) for some recent evidence that financial markets are especially relevant for output quality upgrading.
} 


\section{Appendix C: A version of the model with continuous ef- fort choice between labour and $R \& D$}

The benchmark model assumes that individuals are endowed with two discrete units of time; one of which is always used as production labour, while the other one may be consumed as leisure or alternatively be used as R\&D effort (in this case, either as process innovation or product innovation effort). This ruled out trade-offs between leisure and production effort, and also between $R \& D$ effort and production effort. In addition, the $\{0,1\}$ choice between $R \& D$ effort versus leisure generates a non-convexity in payoffs that translates individuals' choices into a simple comparison of bang-bang solutions. In this appendix we relax these two assumptions, and show how our main results in Section 3 and 4 continue to hold.

We let now $\varepsilon_{l} \in[0,1]$ and $\varepsilon_{r d} \in[0,1]$ denote the effort exerted by the individual in production labour and R\&D, respectively. R\&D effort is given by $\varepsilon_{r d} \equiv \varepsilon_{p}+\varepsilon_{q}$, where $\varepsilon_{p}$ and $\varepsilon_{q}$ still denote process and product innovation effort, respectively. We keep assuming that individuals cannot exert both $\varepsilon_{p}>0$ and $\varepsilon_{q}>0$ at the same time (i.e., they must necessarily specialise in one of the two types of innovation). Henceforth, we replace the utility function in (4) by:

$$
U_{t}=\ln \left[\sum_{q \in Q_{t}} \max \left\{q x(q),[q x(q)]^{q}\right\}\right]+\eta\left(1-\varepsilon_{r d}\right)+\eta\left(1-\varepsilon_{l}\right), \quad \text { with } \eta \geq 1 .
$$

The utility function (58) essentially adds the term $\eta\left(1-\varepsilon_{l}\right)$ to $(4){ }^{32}$

We keep assuming that when an individual exerts R\&D effort, he generates a blueprint and sells it to a firm. The blueprint is sold before anyone knows whether it will turn out to be successful or not. All blueprints carry the same probability to become the successful one. Since innovation effort choices can now take any value within the unit interval, we need to amend a bit their effects relative to what was described in Assumption 1 and $2:^{33}$

Process innovation effort: If individual $i$ alive in $t$ exerts $\varepsilon_{i, t, p}$ units of process innovation effort, and his innovation turns out to be the successful one, this will boost the productivity of each unit of labour effort (in terms of the baseline quality variety output) by $\sigma \varepsilon_{i, t, p}$ units above that of the technology inherited at the beginning of $t$.

Product innovation effort: If individual $i$ alive in $t$ exerts $\varepsilon_{i, t, q}$ units of product innovation effort, and his innovation turns out to be the successful one, this will allow the production of a new quality version of the good with $q_{t}=q_{t-1}+\rho \varepsilon_{i, t, q}$.

\footnotetext{
${ }^{32}$ The assumption $\eta \geq 1$ rather than $\eta>0$-as it was on (4)- is not crucial, and only placed to simplify the exposition by ensuring that the upper-bounds $\varepsilon_{l} \leq 1$ and $\varepsilon_{r d} \leq 1$ never bind in the optimum.

${ }^{33}$ Note that when $\varepsilon_{i, t, p}=1$ or $\varepsilon_{i, t, q}=1$ the points below match the structure defined by Assumption 1 and 2 .
} 


\section{Growth via Process Innovation Effort}

Let us first start again with the simplified framework where individuals can only exert process innovation effort. Like in the benchmark model, we will only focus on pure-strategy symmetric Nash equilibria. Consider a generic individual $i$ alive in period $t$. He will solve:

$$
\max _{\varepsilon_{i, t, l} \in[0,1], \varepsilon_{i, t, p} \in[0,1]}: U_{i, t}=\ln \left(w_{t} \varepsilon_{i, t, l}+S_{t}\left(\varepsilon_{i, t, p}\right)\right)+\eta\left(1-\varepsilon_{i, t, p}\right)+\eta\left(1-\varepsilon_{i, t, l}\right),
$$

where $w_{t}$ denotes the wage per unit of labour effort in $t$ and $S_{t}\left(\varepsilon_{i, t, p}\right)$ denotes the price at which $i$ can sell a blueprint resulting from $\varepsilon_{i, t, p}$ units of process innovation effort. Assuming that neither $\varepsilon_{i, t, l} \leq 1$ nor $\varepsilon_{i, t, p} \leq 1$ bind in the optimum, this yields as FOC:

$$
\begin{aligned}
& \frac{\partial U_{i, t}}{\partial \varepsilon_{i, t, l}}=\frac{w_{t}}{w_{t} \varepsilon_{i, t, l}+S_{t}\left(\varepsilon_{i, t, p}\right)}-\eta \leq 0, \quad \varepsilon_{i, t, l} \geq 0 \quad \text { and } \quad \frac{\partial U_{t}}{\partial \varepsilon_{i, t, l}} \cdot \varepsilon_{i, t, l}=0 ; \\
& \frac{\partial U_{i, t}}{\partial \varepsilon_{i, t, p}}=\frac{S_{t}^{\prime}\left(\varepsilon_{i, t, p}\right)}{w_{t} \varepsilon_{i, t, l}+S_{t}\left(\varepsilon_{i, t, p}\right)}-\eta \leq 0, \quad \varepsilon_{i, t, p} \geq 0 \quad \text { and } \quad \frac{\partial U_{t}}{\partial \varepsilon_{i, t, p}} \cdot \varepsilon_{i, t, p}=0 \text {. }
\end{aligned}
$$

Note that $S_{t}(\cdot)$ is an equilibrium outcome, resulting from the aggregate behaviour of all agents alive in $t$. In a symmetric Nash equilibrium, where $\varepsilon_{j \neq i, t, l}=\varepsilon_{t, l}^{*}$, this will be given by:

$$
S_{t}^{*}\left(\varepsilon_{i, t, p}\right)=\sigma \varepsilon_{t, l}^{*} \varepsilon_{i, t, p}
$$

It is now straightforward to note from (61) that, given the unboundedness of the log utility function, there cannot exist an equilibrium where $\varepsilon_{t, l}^{*}=0$ (as that would mean the return to process innovation effort would be equal to zero, and total income would thus be equal to zero as well). Secondly, replacing (61) into (60), and equalising this to (59), it follows that an equilibrium with positive process innovation effort (i.e., $\varepsilon_{t, p}^{*}>0$ ) must necessarily satisfy $S_{t}^{\prime}\left(\varepsilon_{t, p}^{*}\right)=\sigma \varepsilon_{t, l}^{*}=w_{t}$. This, in turn, means that:

$$
\text { when } \varepsilon_{t, p}^{*}>0 \Rightarrow \varepsilon_{t, l}^{*}=\frac{w_{t}}{\sigma} \text {. }
$$

Plugging (61) and (62) into (59), we can finally obtain

$$
\varepsilon_{t, p}^{*}=\max \left\{0, \frac{1}{\eta}-\frac{w_{t}}{\sigma}\right\} .
$$

Like in the benchmark model, competition by firms for labour implies that the wage in $t$ will be equal to its productivity when using the inherited technology. That is,

$$
w_{t}=\left\{\begin{array}{l}
1+\sigma \sum_{\tau=1}^{t-1} \varepsilon_{\tau, p}^{*} \quad \text { if } t \geq 2 \\
1 \quad \text { if } t=1
\end{array}\right.
$$


Replacing (64) into (63), we thus obtain:

$$
\varepsilon_{t, p}^{*}= \begin{cases}\max \left\{0, \frac{1}{\eta}-\frac{1}{\sigma}-\sum_{\tau=1}^{t-1} \varepsilon_{\tau, p}^{*}\right\} & \text { if } t \geq 2, \\ \max \left\{0, \frac{1}{\eta}-\frac{1}{\sigma}\right\} \quad \text { if } t=1 . & \end{cases}
$$

We can now state a result analogous to the main result in Section $3{ }^{34}$

Result 1 No single economy will be able to sustain positive process innovation effort forever. In particular:

i) If $\sigma \leq \eta$, no process innovation ever takes place in equilibrium. Formally, $\varepsilon_{t, p}^{*}=0$ for all $t \geq 1$. This, in turn, implies that $Y_{t}=\eta^{-1}$ for all $t \geq 1$.

ii) If $\sigma>\eta$, the economy experiences positive process innovation effort only in $t=1$. Formally, $\varepsilon_{1, p}^{*}=\eta^{-1}-\sigma^{-1}>0$ and $\varepsilon_{t, p}^{*}=0$ for all $t \geq 2$. This, in turn, implies that $Y_{1}=\sigma^{-1}$ and $Y_{t}=\sigma \eta^{-2}$ for all $t \geq 2$.

\section{Growth via Product Innovation Effort}

The benchmark model had defined $R_{t-1}$ in (1) as the number of process innovations generated before period $t$. Since $\varepsilon_{t, p}^{*}$ can take any value within $[0,1]$, we now need to slightly amend this definition. We henceforth introduce:

$$
E_{t-1}=\left\{\begin{array}{ll}
\sum_{\tau=1}^{t-1} \varepsilon_{t, p}^{*} & \text { if } t \geq 2 \\
0 & \text { if } t=1
\end{array} .\right.
$$

We now consider a generic period $t \geq 1$, assuming that no product innovation effort has taken place before $t$. When a generic individual $i$ alive in $t$ exerts $\varepsilon_{i, t, q}$ units of product innovation effort, he will generate a blueprint that would be sold to a firm for

$$
\pi_{i, t}^{q}=\left[P_{t}\left(\varepsilon_{i, t, q}\right) \frac{1+\sigma E_{t-1}}{1+\rho \varepsilon_{i, t, q}}-\left(1+\sigma E_{t-1}\right)\right] \varepsilon_{t, l}^{*}
$$

where

$$
P_{t}\left(\varepsilon_{i, t, q}\right)=\left(1+\rho \varepsilon_{i, t, q}\right) Y_{t}^{\rho \varepsilon_{i, t, q} /\left(1+\rho \varepsilon_{i, t, q}\right)} .
$$

denotes the price that the firm will charge for each unit of the quality version $q_{t}=1+\rho \varepsilon_{i, t, q}$, should $i$ 's blueprint turn out to be the successful one.

\footnotetext{
${ }^{34}$ Note that when the equilibrium encompasses $\varepsilon_{t, p}^{*}=0$, condition (59) leads to $\varepsilon_{t, l}^{*}=\eta^{-1}<1$.
} 
Using (66) and (67), it follows that in a (symmetric) Nash equilibrium where all individuals alive in $t$ exert $\varepsilon_{t, q}$ units of product innovation effort (and $\varepsilon_{t, l}$ of production effort), $Y_{t}$ will be given by:

$$
Y_{t}=\left[\varepsilon_{t, l}\left(1+\sigma E_{t-1}\right)\right]^{1+\rho \varepsilon_{t, q}} .
$$

The first result we can now obtain is that there cannot exist an equilibrium with positive product innovation effort when $E_{t-1}=0$. Intuitively, when $E_{t-1}=0$, we will have that $\pi_{i, t}^{q} \leq 0$, and no individual would thus find it optimal to set $\varepsilon_{i, t, q}>0$. Given that $E_{1}=0$, this in turn means that no economy will ever exhibit an equilibrium with product innovation effort in $t=1$.

Given the above result, the question to address now is whether economies satisfying $\sigma>\eta$ will be able to sustain an equilibrium with positive product innovation effort in $t=2$. The following result deals with this question.

Result 2 Consider an economy that satisfies the condition $\sigma>\eta$. This economy will be able to sustain an equilibrium in $t=2$ with positive product innovation effort if and only if $\sigma>\eta^{2} \exp (\eta)$. In particular, when $\sigma>\eta^{2} \exp (\eta)$, there exists an equilibrium in which all individuals set $\varepsilon_{2, q}^{*}>0$. The exact level of $\varepsilon_{2, q}^{*}$ is implicitly pinned down by

$$
\frac{1+\rho \varepsilon_{2, q}^{*}}{\exp \left(\eta \rho \varepsilon_{2, q}^{*}\right)}=\frac{\eta^{2}}{\sigma} \exp (\eta)
$$

which entails that $\varepsilon_{2, q}^{*}$ is increasing in $\sigma$. Moreover, in such and equilibrium $\varepsilon_{2, l}^{*}=\sigma^{-1} \eta \exp (\eta)$ and $Y_{2}^{*}=\exp \left[\eta\left(1+\rho \varepsilon_{2, q}^{*}\right)\right]$.

Proof. Consider a generic individual $i$ alive in $t$. Using (66) and (67), it follows that:

$$
Y_{i, t}\left(\varepsilon_{i, t, q}, \varepsilon_{i, t, l}\right)=\left(1+\sigma E_{t-1}\right)\left[\left(Y_{t}^{\rho \varepsilon_{i, t, q} /\left(1+\rho \varepsilon_{i, t, q}\right)}-1\right) \varepsilon_{t, l}^{*}+\varepsilon_{i, t, l}\right] .
$$

Recalling (58), and using (67), we can observe that (within a symmetric Nash equilibrium with $\varepsilon_{t, l}^{*}$ and $\left.\varepsilon_{t, q}^{*}\right)$, individual $i$ will choose $\varepsilon_{i, t, q}$ and $\varepsilon_{i, t, l}$ by solving the following problem:

$\max _{\varepsilon_{i, t, q} \in[0,1], \varepsilon_{i, t, l} \in[0,1]}: U_{i, t}=\left(1+\rho \varepsilon_{t, q}^{*}\right) \ln \left[\left(Y_{t}^{\frac{\rho \varepsilon_{i, t, q}}{1+\rho \varepsilon_{i, t, q}}}-1\right) \varepsilon_{t, l}^{*}+\varepsilon_{i, t, l}\right]+\eta\left[\left(1-\varepsilon_{i, t, q}\right)+\left(1-\varepsilon_{i, t, l}\right)\right]+\Phi$,

where $\Phi \equiv\left(1+\rho \varepsilon_{t, q}^{*}\right)\left[\ln \left(1+\sigma E_{t-1}\right)-\ln Y_{t}^{\rho \varepsilon_{t, q}^{*} /\left(1+\rho \varepsilon_{t, q}^{*}\right)}\right]$ is a constant from $i$ 's viewpoint. Problem (71) yields as FOC:

$$
\begin{aligned}
\frac{\partial U_{i . t}}{\partial \varepsilon_{i, t, l}} & =\frac{\left(1+\rho \varepsilon_{t, q}^{*}\right)}{\left(Y_{t}^{\rho \varepsilon_{i, t, q} /\left(1+\rho \varepsilon_{i, t, q}\right)}-1\right) \varepsilon_{t, l}^{*}+\varepsilon_{i, t, l}}-\eta \leq 0, \quad \varepsilon_{i, t, l} \geq 0 \quad \text { and } \quad \frac{\partial U_{t}}{\partial \varepsilon_{i, t, l}} \varepsilon_{i, t, l}=0 ; \\
\frac{\partial U_{i, t}}{\partial \varepsilon_{i, t, q}} & =\frac{Y_{t}^{\rho \varepsilon_{i, t, q} /\left(1+\rho \varepsilon_{i, t, q}\right)} \ln \left(Y_{t}\right) \varepsilon_{t, l}^{*}}{\left(1+\rho \varepsilon_{t, q}^{*}\right)\left[\left(Y_{t}^{\frac{\rho \varepsilon_{i, t, q}}{1+\rho \varepsilon_{i, t, q}}}-1\right) \varepsilon_{t, l}^{*}+\varepsilon_{i, t, l}\right]}-\eta \leq 0, \quad \varepsilon_{i, t, q} \geq 0 \text { and } \frac{\partial U_{t}}{\partial \varepsilon_{i, t, q}} \varepsilon_{i, t, q}=0 .
\end{aligned}
$$


Recall we are focusing on symmetric Nash equilibrium. Thus, using (68) we can substitute $Y_{t}=\left[\varepsilon_{t, l}^{*}\left(1+\sigma E_{t-1}\right)\right]^{1+\rho \varepsilon_{t, q}^{*}}$, and solve for $\varepsilon_{i, t, q}^{*}=\varepsilon_{t, q}^{*}$ and $\varepsilon_{i, t, l}^{*}=\varepsilon_{t, l}^{*}$, which leads to: ${ }^{35}$

$$
\begin{aligned}
\frac{\partial U_{t}}{\partial \varepsilon_{t, l}} & =\frac{\left(1+\rho \varepsilon_{t, q}^{*}\right)}{\left(\varepsilon_{t, l}^{*}\right)^{1+\rho \varepsilon_{t, q}^{*}}\left(1+\sigma E_{t-1}\right)^{\rho \varepsilon_{t, q}^{*}}}-\eta=0 \\
\frac{\partial U_{t}}{\partial \varepsilon_{t, q}} & =\ln \left[\varepsilon_{t, l}^{*}\left(1+\sigma E_{t-1}\right)\right]-\eta \leq 0, \quad \varepsilon_{t, q} \geq 0 \quad \text { and } \quad \frac{\partial U_{t}}{\partial \varepsilon_{t, q}} \varepsilon_{t, q}=0 .
\end{aligned}
$$

Let us focus now on $t=2$ when $\sigma>\eta$. Result 1 implies that in this case $E_{1}=\eta^{-1}-\sigma^{-1}$. Therefore, $1+\sigma E_{t-1}=\sigma / \eta$. Replacing this above, it follows that when $\sigma>\eta$ holds, (72) and (73) boil down to:

$$
\begin{aligned}
\frac{\partial U_{2}}{\partial \varepsilon_{2, l}} & =\frac{\left(1+\rho \varepsilon_{2, q}^{*}\right)}{\left(\varepsilon_{2, l}^{*}\right)^{1+\rho \varepsilon_{2, q}^{*}}\left(\frac{\sigma}{\eta}\right)^{\rho \varepsilon_{2, q}^{*}}-\eta=0} \\
\frac{\partial U_{2}}{\partial \varepsilon_{2, q}} & =\ln \left(\varepsilon_{2, l}^{*} \frac{\sigma}{\eta}\right)-\eta \leq 0, \quad \varepsilon_{2, q} \geq 0 \quad \text { and } \quad \frac{\partial U_{2}}{\partial \varepsilon_{2, q}} \varepsilon_{2, q}=0 .
\end{aligned}
$$

Using (75), we can then observe that when $\varepsilon_{2, l}^{*}<\sigma^{-1} \eta \exp (\eta)$, the equilibrium will exhibit $\varepsilon_{2, q}^{*}=0$. Then, replacing $\varepsilon_{2, q}^{*}=0$ into (72) we obtain $\varepsilon_{2, l}^{*}=\eta^{-1}$. As a result, when $\sigma \leq$ $\eta^{2} \exp (\eta)$, in the equilibrium, $\varepsilon_{2, q}^{*}=0$ will hold true.

Using again (75), we can see that for $\varepsilon_{2, q}^{*}>0$ to hold, it must be the case that $\varepsilon_{2, l}^{*}=$ $\sigma^{-1} \eta \exp (\eta)$. Replacing this expression into (72) leads to the expression in (69). Lastly, let now $\phi\left(\varepsilon_{2, q}^{*}\right) \equiv\left(1+\rho \varepsilon_{2, q}^{*}\right) e^{-\eta \rho \varepsilon_{2, q}^{*}}$ and notice that $\phi(0)=1$ and $\phi^{\prime}\left(\varepsilon_{2, q}^{*}\right)<0$. Therefore, it follows that when $\sigma>\eta^{2} \exp (\eta)$ there is one value of $\varepsilon_{2, q}^{*}>0$ that satisfies (69). Moreover, since $\phi^{\prime}\left(\varepsilon_{2, q}^{*}\right)<0, \varepsilon_{2, q}^{*}$ is non-decreasing in $\sigma$. Notice finally that the fact that $\sigma>\eta^{2} \exp (\eta)$, in turn implies that $\varepsilon_{2, l}^{*}=\sigma^{-1} \eta \exp (\eta)<1$, satisfying thus the upper-bound constraint on $\varepsilon_{2, l}^{*}$.

\section{Effect of Product Innovation on Process Innovation Effort}

This final subsection illustrates how our previous findings in Section 4.4 extend to this alternative version of the model. In the sake of brevity, we will restrict the analysis to the case of an economy that satisfies the parametric condition $\sigma>\eta^{2} \exp (\eta)$. We will study the level of process innovation effort that would take place in an equilibrium in $t=3$, following an equilibrium in $t=2$ with $\varepsilon_{2, q}^{*}>0$. In short, this subsection shows that this will lead to a positive level of process innovation effort in $t=3$. As in the benchmark model, the reason for this result

\footnotetext{
${ }^{35}$ The FOC (72) is already explicitly taking into account that (due to the unboundedness of the log utility function) there cannot exist and equilibrium with $\varepsilon_{t, l}^{*}=0$.
} 
rests on the positive effect that (past) product innovations entail on the incentives to further undertake process innovation effort.

Consider a generic individual $i$ in $t=3$ who exerts $\varepsilon_{i, 3, l} \in[0,1]$ and $\varepsilon_{i, 3, p} \in[0,1]$. He will receive as total income

$$
Y_{i, 3}=w_{3} \varepsilon_{i, 3, l}+S_{3}\left(\varepsilon_{i, 3, p}\right)=\underbrace{P_{3}\left(q_{2}\right) \frac{1+\sigma E_{1}}{1+\rho \varepsilon_{2, q}^{*}}}_{w_{3}} \varepsilon_{i, 3, l}+\underbrace{\sigma \varepsilon_{3, l}^{*} \varepsilon_{i, 3, p}}_{S_{3}\left(\varepsilon_{i, 3, p}\right)} .
$$

Combining (76) with (58), it follows that $i$ will choose $\varepsilon_{i, 3, l}$ and $\varepsilon_{i, 3, p}$ by solving:

$\max _{\varepsilon_{i, 3, l} \in[0,1], \varepsilon_{i, 3, p} \in[0,1]}: U_{i, 3}=\left(1+\rho \varepsilon_{2, q}^{*}\right) \ln \left[\left(1+\sigma E_{1}\right) \varepsilon_{i, 3, l}+\sigma \varepsilon_{3, l}^{*} \varepsilon_{i, 3, p}\right]+\eta\left[\left(1-\varepsilon_{i, 3, p}\right)+\left(1-\varepsilon_{i, 3, l}\right)\right]$.

This yields the following FOC:

$$
\begin{aligned}
\frac{\partial U_{i, t}}{\partial \varepsilon_{i, 3, l}}=\frac{\left(1+\rho \varepsilon_{2, q}^{*}\right)\left(1+\sigma E_{1}\right)}{\left(1+\sigma E_{1}\right) \varepsilon_{i, 3, l}+\sigma \varepsilon_{3, l}^{*} \varepsilon_{i, 3, p}}-\eta \leq 0, \quad \varepsilon_{i, 3, l} \geq 0 \quad \text { and } \quad \frac{\partial U_{t}}{\partial \varepsilon_{i, 3, l}} \cdot \varepsilon_{i, 3, l}=0 \\
\frac{\partial U_{i, t}}{\partial \varepsilon_{i, 3, p}}=\frac{\left(1+\rho \varepsilon_{2, q}^{*}\right) \sigma \varepsilon_{3, l}^{*}}{\left(1+\sigma E_{1}\right) \varepsilon_{i, 3, l}+\sigma \varepsilon_{3, l}^{*} \varepsilon_{i, 3, p}}-\eta \leq 0, \quad \varepsilon_{i, 3, p} \geq 0 \quad \text { and } \quad \frac{\partial U_{t}}{\partial \varepsilon_{i, 3, p}} \cdot \varepsilon_{i, 3, p}=0
\end{aligned}
$$

It is easy to show again that in a symmetric Nash equilibrium it must be the case that $\varepsilon_{2, q}^{*}>$ 0 , therefore (77) must hold with strict equality. In turn, this implies that for an equilibrium in $t=3$ to encompass $\varepsilon_{3, p}^{*}>0$, it must be that $\sigma \varepsilon_{3, l}^{*}=\left(1+\sigma E_{1}\right)$. Hence, using the fact that when $\sigma>\eta^{2} \exp (\eta)$, we have $E_{1}=\sigma / \eta$, we can observe that:

$$
\text { when } \varepsilon_{3, p}^{*}>0 \Rightarrow \varepsilon_{3, l}^{*}=\frac{1}{\eta} \text {. }
$$

Lastly, plugging (79), together with $\sigma \varepsilon_{3, l}^{*}=\left(1+\sigma E_{1}\right)$, into (78), and letting this condition hold with strict equality, leads to the following result.

Result 3 Consider an economy that satisfies $\sigma>\eta^{2} \exp (\eta)$ and that in $t=2$ has exhibited an equilibrium with $\varepsilon_{2, q}^{*}>0$, where $\varepsilon_{2, q}^{*}$ was determined by condition (69). Then, this economy will generate enough incentives to sustain an equilibrium in $t=3$ with positive process innovation effort. In such an equilibrium,

$$
\varepsilon_{3, p}^{*}=\frac{\rho \varepsilon_{2, q}^{*}}{\eta}
$$

Proof. Suppose first that in equilibrium $\varepsilon_{i, 3, p}=0$. Plugging this into (77), yields $\varepsilon_{i, 3, l}=$ $\left(1+\rho \varepsilon_{2, q}^{*}\right) / \eta$. Next, using $\varepsilon_{i, 3, l}=\varepsilon_{3, l}^{*}=\left(1+\rho \varepsilon_{2, q}^{*}\right) / \eta$ together with $\varepsilon_{i, 3, p}=0$ into (78), implies that, for this to be an optimum, $\left(1+\rho \varepsilon_{2, q}^{*}\right) \leq 1$ must be verified. However, this cannot be true when $\varepsilon_{2, q}^{*}>0$, hence it must be that the equilibrium will require $\varepsilon_{i, 3, p}>0$. Finally, to prove that $\varepsilon_{3, p}^{*}=\rho \varepsilon_{2, q}^{*} / \eta$, solve (78) as a strict equality, after plugging in $\varepsilon_{i, 3, l}=\varepsilon_{3, l}^{*}=\eta^{-1}$ therein, and bearing in mind that $E_{1}=\eta^{-1}-\sigma^{-1}$. 


\section{Appendix D: A diagrammatic depiction of the dynamic path in the two-quality-version model}

This appendix provides a diagrammatic description of the dynamic path of an economy where $Q=\{1,1+\rho\}$, depending on the value of $\sigma$ that applies to it. The dynamics for innovation effort will follow from the two panels in Figure 1. The upper panel plots the threshold functions $\bar{R}(\sigma), \underline{R}_{1}(\sigma)$ and $\underline{R}_{2}(\sigma)$, as specified in (12), (20) and (21), respectively. The lower panel plots again the threshold function $\bar{R}(\sigma)$, and it includes the period-level threshold functions $\bar{t}(\sigma)$ and $\underline{t}(\sigma)$; the former as (thicker) dashed lines and the latter as (thinner) solid lines. (Notice that $\bar{t}(\sigma)$ is weakly increasing in $\sigma$, while $\underline{t}(\sigma)$ is weakly decreasing in $\sigma$.) The lower panel in Figure 1 includes also another function of $\sigma$, denoted by $T(\sigma)$. The function $T(\sigma)$ pins down the values of $\underline{t}$ for which the LHS of (25) equals $\eta .^{36}$

Consider first the case when product innovation is barred from the model (as in Section 3). Economies whose $\sigma \leq e^{\eta}-1$ will never undertake process innovation, and their incomes will remain fixed at $Y_{t}=1$. Economies with $e^{\eta}-1<\sigma \leq \sigma_{a}$ will undertake process innovation only in $t=1$, and their incomes will be equal to $Y_{t}=1+\sigma$ for all $t \geq 1$. Next, economies with $\sigma \in\left(\sigma_{a}, \sigma_{b}\right]$ will undertake process innovation in $t=1$ and $t=2$; the incomes for this set of economies will be $Y_{1}=1+\sigma$ and $Y_{t}=1+2 \sigma$ for any $t \geq 2$. Similarly, economies with $\sigma \in\left(\sigma_{b}, \sigma_{c}\right]$ will undertake process innovation in every period until $t=3$, exhibiting an income path with $Y_{1}=1+\sigma, Y_{2}=1+2 \sigma$, and $Y_{t}=1+3 \sigma$ for any $t \geq 3{ }^{37}$

Let us move on now to the case when product innovation is allowed into the model. Notice first that for the sets of economies discussed in the above paragraph, the dynamics remain unaltered. This is because, for any $\sigma \leq \sigma_{c}$ we have that $\underline{t}(\sigma)>\bar{t}(\sigma)$. Instead, when $\sigma>\sigma_{c}$ dynamics will be affected by the introduction of product innovation, as in these cases $\underline{t}(\sigma) \leq$ $\bar{t}(\sigma)$. In particular, economies for which $\sigma \in\left(\sigma_{c}, \sigma_{d}\right]$ will undertake process innovation until $t=4$, and in $t=5$ they will switch to an equilibrium with positive product innovation effort. Similarly, economies whose $\sigma \in\left(\sigma_{d}, \sigma_{f}\right]$ will exhibit an equilibrium with $\varepsilon_{t, p}=1$ until $t=3$, and will switch to an equilibrium with $\varepsilon_{t, q}=1$ in $t=4 .^{38}$

\footnotetext{
${ }^{36}$ The formal expression of this function is: $T(\sigma)=\left[1+\sigma-e^{\eta /(1+\rho)}\right]\left[\sigma\left(e^{\eta /(1+\rho)}-1\right)\right]^{-1}$. Comparing this expression to (12), we can observe that $T(\sigma)>\underline{R}(\sigma)$ for any $\sigma$.

${ }^{37} \mathrm{~A}$ similar reasoning straightforwardly applies to economies whose $\sigma \in\left(\sigma_{c}, \sigma_{e}\right]$ and $\sigma \in\left(\sigma_{e}, \sigma_{g}\right]$. The former undertake process innovation until $t=4$ and reach an income level $Y_{t}=1+4 \sigma$ in any $t \geq 4$; the latter undertake process innovation until $t=5$ and reach an income level $Y_{t}=1+5 \sigma$ in any $t \geq 5$.

${ }^{38}$ Analogously, an economy whose $\sigma$ is just above $\sigma_{f}$ will switch to an equilibrium with $\varepsilon_{t, q}=1$ in $t=3$.
} 
The lower panel in Figure 1 also informs us of what happens in the period right after the economy switches to an equilibrium with product innovation. Consider, for example, an economy with $\sigma=\bar{\sigma} \in\left(\sigma_{c}, \sigma_{d}\right)$. This economy switches to an equilibrium with product innovation in $t=5$. What happens next in $t=6$ ? Since $\underline{t}(\bar{\sigma})=4$ and $T(\bar{\sigma})>4$, condition (25) holds for this economy in $t=6$. Therefore, an economy with $\sigma=\bar{\sigma}$ will undertake process innovation effort again in $t=6$. Interestingly, notice that $\bar{t}(\bar{\sigma})=4$, hence condition (26) would fail to hold for this economy. This means that, in the absence of product innovation effort, an economy with $\sigma=\bar{\sigma}$ would not be able to sustain five subsequent rounds of process innovation effort as equilibrium outcomes. Only when product innovation effort is allowed, will this economy be able to display a fifth round of process innovation effort (which will take place in $t=6$, after the equilibrium with product innovation effort in $t=5$ ). In other words, product innovation effort in $t=5$ allows an economy with $\sigma=\bar{\sigma}$ to sustain growth for longer.

Figure 2 depicts how the ability/inability to switch to an equilibrium with product innovation effort ends up magnifying income disparities among economies with slightly different levels of $\sigma$. This figure plots the income path for two economies differing in $\sigma$ : the solid lines show the income path when $\sigma=\bar{\sigma}$, whereas the dashed lines do so for $\sigma=\underline{\sigma}$. Notice from Figure 1 that $\underline{\sigma} \in\left(\sigma_{b}, \sigma_{c}\right)$. Up until $t=3$ the income paths diverge from each other due to gaps in labour productivity increases when $\bar{\sigma}>\underline{\sigma}$. After $t=3$, growth stops forever in the $\underline{\sigma}$-economy, while it continues in the $\bar{\sigma}$-economy until $t=6$. In $t=4$ due to process innovation, next in $t=5$ owing to product innovation effort and, lastly, in $t=6$ again as a result of process innovation effort. Figure 2 displays also the income path that the $\bar{\sigma}$-economy would have followed in the absence of product innovation effort in $t=5$ : this is shown by the dotted line at the level $Y_{t}=1+4 \bar{\sigma}$. As we can see, in the absence of product innovation in $t=5$ income disparities between the two economies would have ended up narrower, and stop widening beyond $t=4$.

\section{Appendix E: Additional Proofs}

1. Proof that $[q x(q)]^{q} \geq q x(q)$ always holds true in equilibrium for $q=1+\rho$. Suppose that for $q=1+\rho$ we have that $[q x(q)]^{q}<q x(q)$. Then, (4) simplifies to:

$$
U_{t}=\ln \left[x_{1}+(1+\rho) x_{(1+\rho)}\right]+\eta(1-\varepsilon),
$$

where we are using $x_{q}$ to denote the quantity of the version $q=1,(1+\rho)$ consumed by the individual. Given the above expressions, it follows that the maximum price that could be charged for each unit of the version $q=1+\rho$ will be: 


$$
P_{t}=1+\rho
$$

Since firms intend to maximise profits, (C.1) would be also the equilibrium price. Recall now that the inherited technology from the pre-historic period $t=0$ allows the production of one unit of the baseline quality version with one unit of labour, and all individuals are endowed with one labour time. As a consequence of this, the minimum wage level that could possibly hold in equilibrium is one. Since the income of an individual cannot be smaller that his wage, also the lowest income level that could possibly hold in equilibrium is equal to one. In other words, in equilibrium, $Y_{t} \geq 1$ for any $t$. Let us use now the fact that $Y_{t} \geq 1$, together with the equilibrium price when $[q x(q)]^{q}<q x(q)$ holds for $q=1+\rho$ given by (C.1). Bearing in mind that $x_{(1+\rho)}=Y_{t} / P_{t}$, it follows that $x_{(1+\rho)} \geq 1 /(1+\rho)$. But, when $x_{(1+\rho)} \geq 1 /(1+\rho)$, we have that $(1+\rho) x_{(1+\rho)} \geq 1$, and therefore it must be that $\left[(1+\rho) x_{(1+\rho)}\right]^{1+\rho} \geq(1+\rho) x_{(1+\rho)}$, contradicting our initial assumption.

\section{Proof that the threshold $\underline{R}_{2}$ is a decreasing function of $\sigma$.}

Note that an alternate way to implicitly define $\underline{R}_{2}$ is by applying logs on (21). This leads to:

$$
\underbrace{(1+\rho) \ln \left(1+\sigma \underline{R}_{2}\right)-\ln \left(1+\sigma \underline{R}_{2}+\sigma\right)}_{\Gamma\left(\rho, \sigma, \underline{R}_{2}\right)}=0 .
$$

From (C.2) we can observe several important properties of the function $\left.\Gamma\left(\rho, \sigma, \underline{R}_{2}\right): i\right) \Gamma_{\underline{R}_{2}}^{\prime}(\cdot)>$ 0 , ii $) \Gamma_{\rho}^{\prime}(\cdot)>0$, iii $\left.) \Gamma\left(\rho, \sigma, \underline{R}_{2}=0\right)=-\ln (1+\sigma)<0, i v\right) \lim _{\underline{R}_{2} \rightarrow \infty} \Gamma\left(\rho=0, \sigma, \underline{R}_{2}\right)=0$. A first result to notice is that since $\Gamma\left(\rho=0, \sigma, \underline{R}_{2}=\infty\right)=0$ for any $\sigma>0$, and we have that $\Gamma_{\rho}^{\prime}(\cdot)>0$, it must then be that for any $\rho>0$ there is a unique, finite and strictly positive value of $\underline{R}_{2}$ such that it satisfies $\Gamma\left(\rho, \sigma, \underline{R}_{2}\right)=0$. Furthermore, combining this with $\Gamma_{\underline{R}_{2}}^{\prime}(\cdot)>0$, it follows that $\partial \underline{R}_{2} / \partial \rho<0$. Using now the full expression $\Gamma_{\rho}^{\prime}(\cdot)=\ln \left(1+\sigma \underline{R}_{2}\right)$, we can also see that $\partial \Gamma_{\rho}^{\prime}(\cdot) / \partial \sigma>0$. Since $\Gamma\left(\rho=0, \sigma, \underline{R}_{2}=\infty\right)=0$ for any $\sigma>0$, and $\Gamma_{\rho}^{\prime}(\cdot)>0$, it must then be the case that, considering two generic $\underline{\sigma}<\bar{\sigma}$ and letting $\Gamma\left(\rho, \underline{\sigma}, \underline{R}_{2}(\underline{\sigma})\right)=0$ and $\Gamma\left(\rho, \bar{\sigma}, \underline{R}_{2}(\bar{\sigma})\right)=0$, we must have $\underline{R}_{2}(\bar{\sigma})<\underline{R}_{2}(\underline{\sigma})$.

3. Proof of existence of a single and simultaneous crossing point for all three threshold functions $\bar{R}(\sigma), \underline{R}_{1}(\sigma)$ and $\underline{R}_{2}(\sigma)$ when $\sigma=e^{\eta / q}\left(e^{\eta}-1\right)$.

From (12) and (20) it follows that $\bar{R}(\sigma)=\underline{R}_{1}(\sigma)$ if and only if $\sigma=\widetilde{\sigma} \equiv e^{\eta / \rho}\left(e^{\eta}-1\right)$. At that crossing point, we have that $\underline{R}_{1}(\widetilde{\sigma})=\left(e^{\eta / \rho}-1\right) / e^{\eta / \rho}\left(e^{\eta}-1\right)$. Next, plugging the RHS of $(20)$ into the LHS of (21), we can observe that $\underline{R}_{1}(\sigma)=\underline{R}_{2}(\sigma)$ if and only if the following equality holds: $\left(e^{\eta / \rho}\right)^{1+\rho}=e^{\eta / \rho}+\sigma$. Since this equality holds if and only if $\sigma=e^{\eta / \rho}\left(e^{\eta}-1\right)$, it then follows that all the three threshold functions $\left[\bar{R}(\sigma), \underline{R}_{1}(\sigma)\right.$ and $\left.\underline{R}_{2}(\sigma)\right]$ must necessarily cross each other once, and only once, and all at the same value of $\sigma$, given by $\widetilde{\sigma}$. 


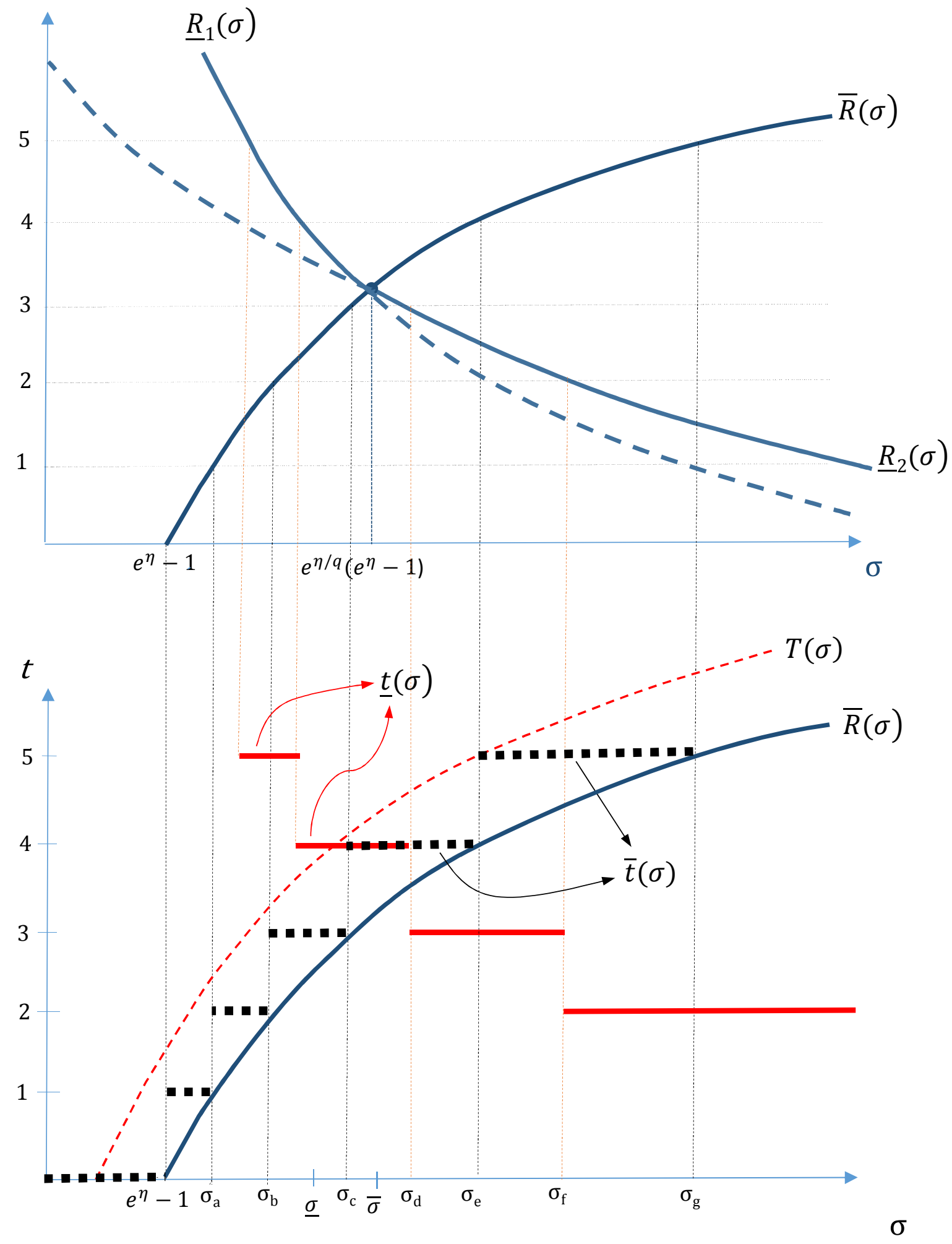

Figure 1: Equilibrium Innovation Effort 


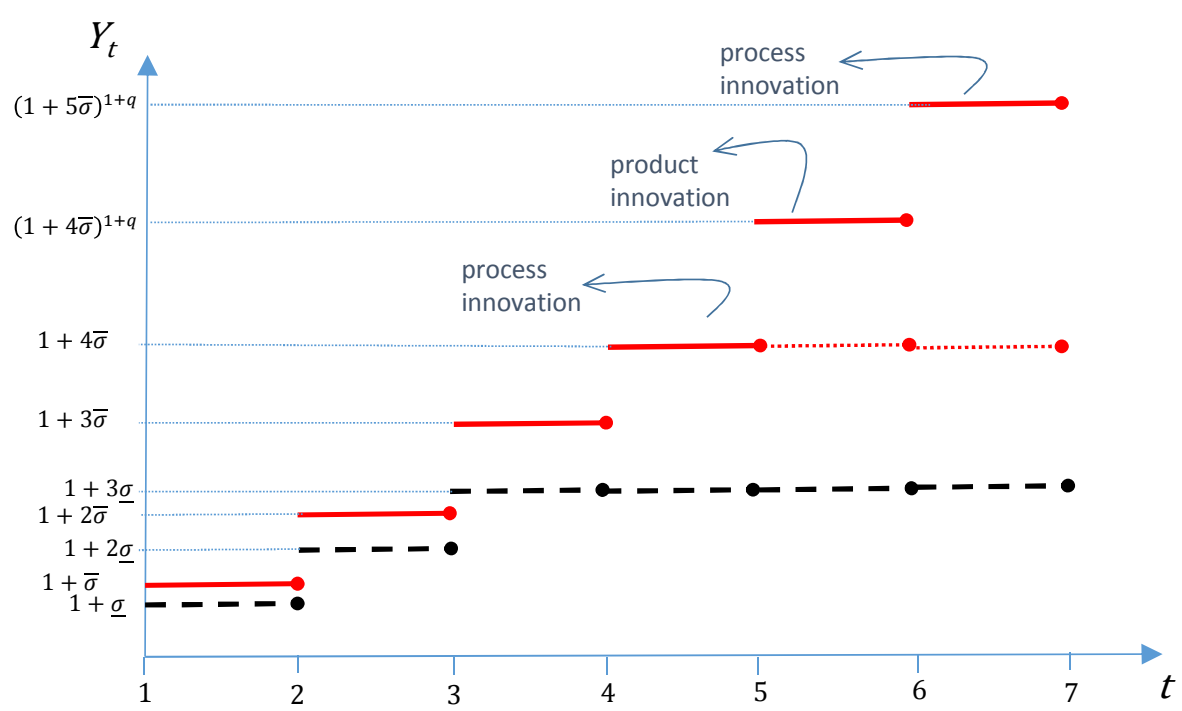

Figure 2: Income Paths 


\section{References}

[1] Aghion, P. and Howitt, P. (1992) 'A Model of Growth Through Creative Destruction', Econometrica, vol. 60, pp. 323-351.

[2] Aghion, P. and Howitt, P. (1996). 'Research and Development in the Growth Process', Journal of Economic Growth, vol. 1, pp. 49-73.

[3] Bas, M. and Strauss-Kahn, V. (2015) 'Input-trade liberalization, export prices and quality upgrading', Journal of International Economics, vol. 95, pp. 250-262.

[4] Bils, M., and Klenow, P. (2001). 'Quantifying quality growth', American Economic Review, vol. 91, pp. 1006-1030.

[5] Brambilla, I., Lederman, D. and Porto, G. (2012). 'Exports, Export Destinations, and Skills', American Economic Review, vol. 102, pp. 3406-3438.

[6] Bresnahan, T. and Trajtenberg, M. (1995). 'General purpose technologies 'Engines of growth'?', Journal of Econometrics, vol. 65, pp. 83-108.

[7] Choi, Y. C., Hummels, D. and Xiang, C. (2009). 'Explaining Import Quality: The Role of the Income Distribution', Journal of International Economics, vol. 77, pp. 265-275.

[8] Chu, A. C., Cozzi, G. and Galli, S. (2012). 'Does intellectual monopoly stimulate or stifle innovation?', European Economic Review, vol. 56, pp. 727-746.

[9] Cohen, W. M. and Klepper, S. (1996) 'Firm size and the nature of innovation within industries: the case of process and product R\&D', Review of Economics and Statistics, vol. 78, pp. 232-243.

[10] Crino, R. and Ogliari, L. (2017). 'Financial Imperfections, Product Quality, and International Trade', Journal of International Economics, vol. 104, pp. 63-84.

[11] Fajgelbaum, P., Grossman, G. and Helpman, E. (2011). 'Income Distribution, Product Quality, and International Trade', Journal of Political Economy, vol. 119, pp. 721-765.

[12] Fajgelbaum, P., Grossman, G. and Helpman, E. (2015). 'A Linder hypothesis for foreign direct investment', Review of Economic Studies, vol. 82, pp. 83-121.

[13] Flach, L. (2016). 'Quality Upgrading and Price Heterogeneity: Evidence from Brazilian exporters', Journal of International Economics, vol. 102, pp. 282-290 
[14] Flam, H. and Helpman, E. (1987). 'Vertical Product Differentiation and North-South Trade', American Economic Review, vol. 77, pp. 810-822.

[15] Foellmi, R. and Zweimüller, J. (2006). 'Income Distribution and Demand-Induced Innovations', Review of Economic Studies, vol. 73, pp. 941-960.

[16] Foellmi, R., Wuergler, T. and Zweimüller, J. (2014). 'The Macroeconomics of Model T', Journal of Economic Theory, vol. 153, pp. 617-647.

[17] Francois, P. and Lloyd-Ellis, H. (2003). 'Animal Spirits Through Creative Destruction', American Economic Review, vol. 93, pp. 530-550.

[18] Grossman, G. and Helpman, E. (1991a). 'Quality ladders in the theory of growth', Review of Economic Studies, vol. 58, pp. 43-61.

[19] Grossman, G. and Helpman, E. (1991b). 'Quality ladders and product cycles', Quarterly Journal of Economics, vol. 106, pp. 557-586.

[20] Grossman, G. and Helpman, E. (1991c). Innovation and Growth in the Global Economy. MIT Press.

[21] Hallak, J. C. (2006). 'Product Quality and the Direction of Trade', Journal of International Economics, vol. 68, pp. 238-265.

[22] Harrison, R., Jaumandreu, J., Mairesse, J. and Peters, B. (2014). 'Does innovation stimulate employment? A firm-level analysis using comparable micro-data from four European countries', International Journal of Industrial Organization, vol. 35, pp. 29-43.

[23] Helpman, E. and Tratjenberg, M. (1998a). 'A time to sow and a time to reap: growth based on general purpose technologies'. In: Helpman, E. (Ed.), General Purpose Technologies and Economic Growth. MIT Press.

[24] Helpman, E. and Tratjenberg, M. (1998b). 'Diffusion of general purpose technologies'. In: Helpman, E. (Ed.), General Purpose Technologies and Economic Growth. MIT Press.

[25] Huergo, E. and Jaumandreu, J. (2004). 'How does probability of process innovation change with firm age?', Small Business Economics, vol. 22, pp. 193-207.

[26] Jaimovich, E. and Merella, V. (2012). 'Quality Ladders in a Ricardian Model of Trade with Nonhomothetic Preferences', Journal of the European Economic Association, vol. 10, pp. 908937. 
[27] Jaimovich, E. and Merella, V. (2015). 'Love for Quality, Comparative Advantage, and Trade', Journal of International Economics, vol. 97, pp. 376-391.

[28] Jones, C. I. (1995). 'R \& D-based models of economic growth', Journal of political Economy, vol. 103, pp. 759-784.

[29] Jovanovic, B. and Nyarko, Y. (1996).'Learning by doing and the choice of technology', Econometrica, vol. 64, pp. 1299-1310.

[30] Jovanovic, B. and Rob, R. (1990). 'Long waves and short waves: Growth through intensive and extensive search', Econometrica, vol. 58 ,pp.1391-1409.

[31] Judd, K. L. (1985). 'On the performance of patents', Econometrica, vol. 53, pp. 567-585.

[32] Kortum, S. (1997) 'Research, patenting, and technological change', Econometrica, vol. 65, pp. 1389-1419.

[33] Manova, K. and Zhang, Z. (2012). 'Export Prices across Firms and Destinations', Quarterly Journal of Economics, vol. 127, pp. 379-436.

[34] Matsuyama, K. (1999). 'Growing Through Cycles', Econometrica, vol. 67, pp. 335-347.

[35] Matsuyama, K. (2002). 'The Rise of Mass Consumption Societies', Journal of Political Economy, vol. 110, pp. 1035-1070.

[36] Murphy K., Shleifer A. and Vishny R. (1989). 'Industrialization and the Big Push', Journal of Political Economy, vol. 97, 1003-1026.

[37] Murphy, K. and Shleifer, A. (1997). 'Quality and Trade', Journal of Development Economics, vol. 53, pp. 1-15.

[38] Parisi, M., Schiantarelli, F., Sembenelli, A. (2006). 'Productivity, innovation and R\&D: micro evidence for Italy', European Economic Review, vol. 50, pp. 2037-2061.

[39] Peretto, P. and Connolly, M. (2007). 'The manhattan metaphor', Journal of Economic Growth, vol. 12 , pp. 329-350.

[40] Redding, S. (2002). 'Path dependence, endogenous innovation, and growth', International Economic Review, Vol. 43, pp. 1215-1248.

[41] Romer, P. (1990). 'Endogenous Technological Change', Journal of Political Economy, vol. 98, pp. 71-102. 
[42] Segerstrom, P. (1998).'Endogenous Growth without Scale Effect', American Economic Review, vol. 88 , pp. $1290-1310$.

[43] Segerstrom, P., Anant, T. and Dinopoulos, E. (1990).'A Schumpeterian model of the product life cycle', American Economic Review, vol. 80, pp. 1077-1091.

[44] Shleifer, A. (1986) 'Implementation cycles', Journal of Political Economy, vol. 94, pp. 1163-1190.

[45] Sorger, G. (2011). 'Horizontal innovations with endogenous quality choice', Economica, vol. 78, pp. 697-722.

[46] Stein, J. (1997). 'Waves of Creative Destruction: Firm-Specific Learning-by-Doing and the Dynamics of Innovation', Review of Economic Studies, vol. 64, pp. 265-288.

[47] Stokey, N. (1991). 'Human Capital, Product Quality, and Growth', Quarterly Journal of Economics, vol. 106, pp. 587-616.

[48] Verhoogen, E. (2008). 'Trade, Quality Upgrading and Wage Inequality in the Mexican Manufacturing Sector', Quarterly Journal of Economics, vol. 123, pp 489-530.

[49] Young, A. (1993). 'Invention and Bounded Learning by Doing', Journal of Political Economy, vol. 101, pp. 443-72. 